\title{
IMPACT OF NICOTINE WITHDRAWAL AND POSTCESSATION SELF-EFFICACY ON SHORT-TERM ABSTINENCE FROM SMOKING
}

\author{
by \\ Ashley Catherine Armstrong \\ A thesis submitted to the Faculty of Graduate and Postdoctoral Affairs \\ in partial fulfillment of the requirements for the degree of \\ Master of Arts \\ in \\ Psychology
}

Carleton University

Ottawa, Ontario

(C)2014

Ashley Catherine Armstrong 


\begin{abstract}
Nicotine withdrawal is cited by smokers as a principal reason for relapse and a significant barrier to sustained abstinence. Postcessation self-efficacy has been established as a predictor of smoking cessation success but may be influenced by the impact of nicotine withdrawal symptoms. The objective of the current study was to determine if the relationship between nicotine withdrawal and relapse to smoking was mediated by diminished postcessation self-efficacy. Smokers $(N=266)$ ready to make a quit attempt completed measures of nicotine withdrawal, depressed mood and selfefficacy at Week 1 post-target quit date (TQD); smoking status was collected at Week 3 post-TQD. Both nicotine withdrawal $(O R=0.56, C l=0.36-0.85, p<.01)$ and self-efficacy $(O R=1.50, C l=1.09-2.05, p<.05)$ predicted continuous abstinence at Week 3;

depressed mood did not. Mediational analysis did not support the contention that selfefficacy mediated the role of nicotine withdrawal on abstinence.
\end{abstract}




\section{Acknowledgments}

My deepest thanks to Dr. Andrew Pipe and Dr. Joanna Pozzulo for providing me with this opportunity to further my studies; I am so grateful for your guidance, support and patience throughout this process. I would like to thank Dr. Andrea Howard for generously offering her time and statistics mentorship as well as my committee members Dr. Bernadette Campbell and Dr. Diana Majury. I would like to acknowledge the research staff in the Division of Prevention \& Rehabilitation at the University of Ottawa Heart Institute, specifically Dr. Bob Reid who has provided me with invaluable research training over the years, and Debbie Aitken and Lisa McDonnell for their constant support, advice and listening ear. I would like to thank my parents, Delmer and Catherine, my sisters, Stacey and Lindsay and my cheering squad Yvonne, Pam, Nikki, Bonnie, Penny and Angela for their constant encouragement and relentless support during this endeavour. 


\section{Table of Contents}

Title Page

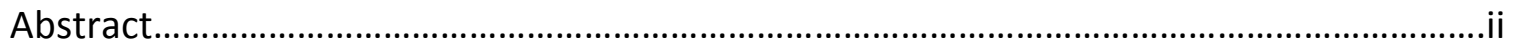

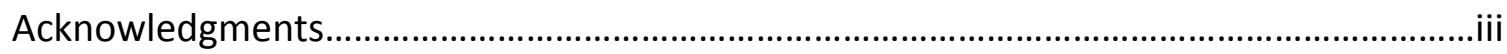

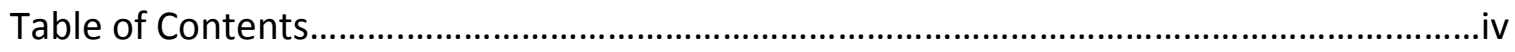

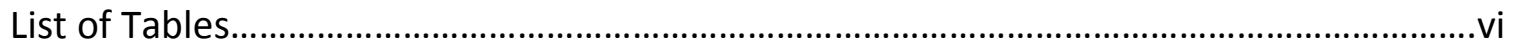

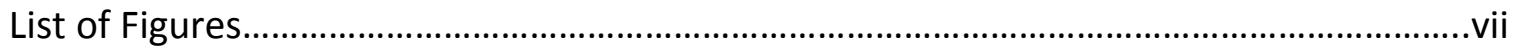

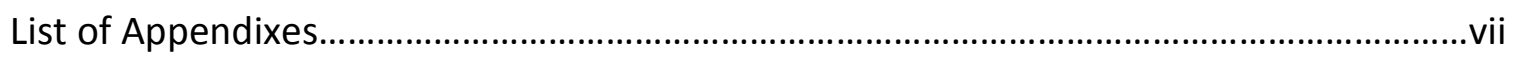

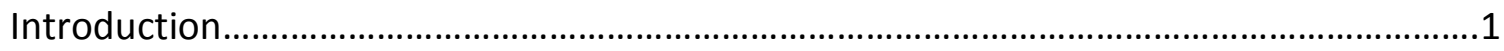

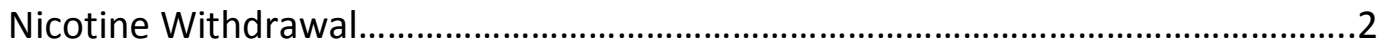

Prevalence of Nicotine Withdrawal Symptoms....................................................

Nicotine Withdrawal and Smoking Cessation Outcomes.......................................

Postcessation Depressed Mood and Smoking Cessation Outcomes.....................10

Self-Efficacy and Smoking Cessation Outcomes..................................................14

Postcessation Self-Efficacy and Symptoms of Nicotine Withdrawal.....................18

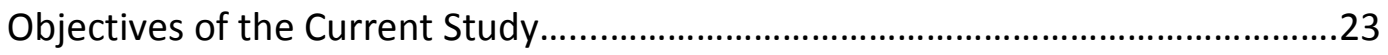

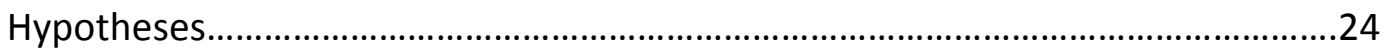

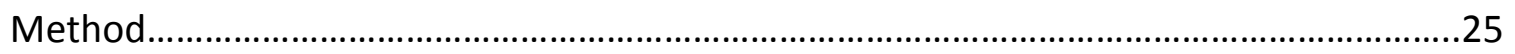

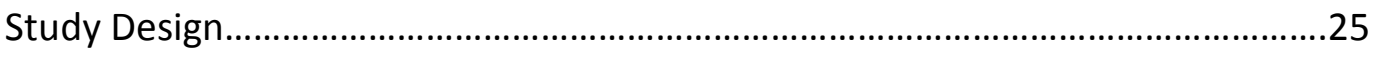

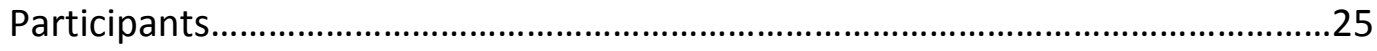

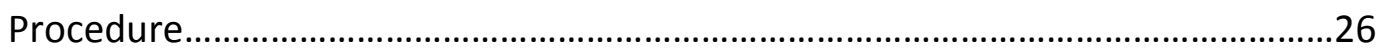

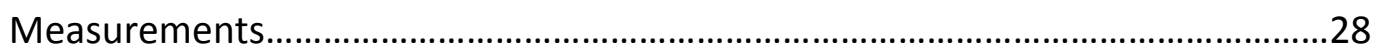




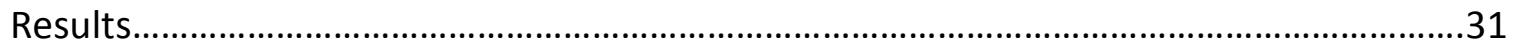

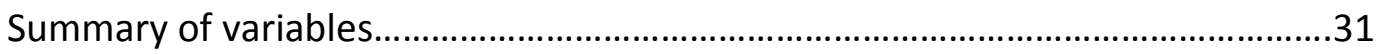

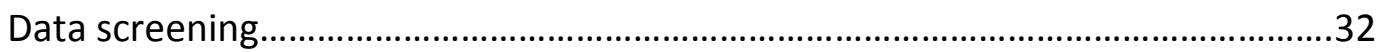

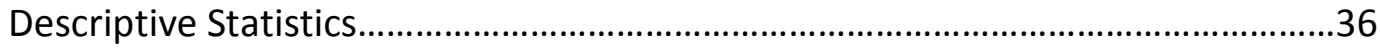

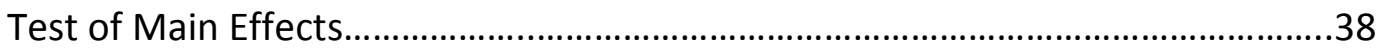

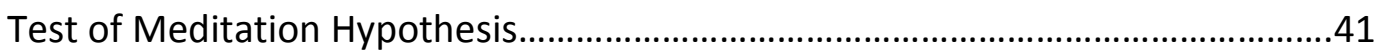

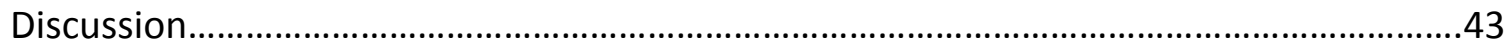

Main Effects Analyses.......................................................................................4

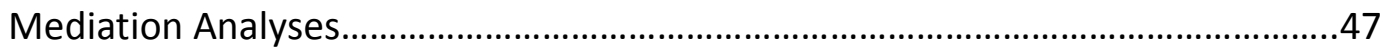

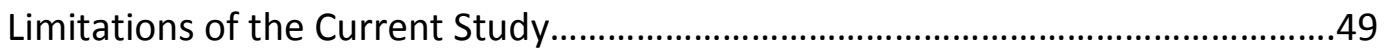

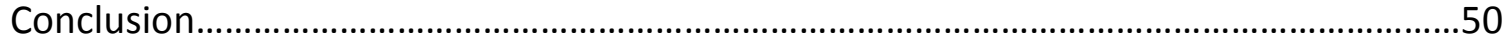

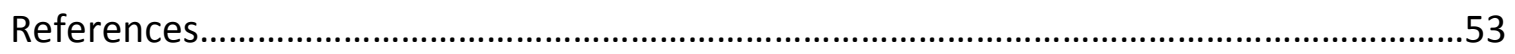

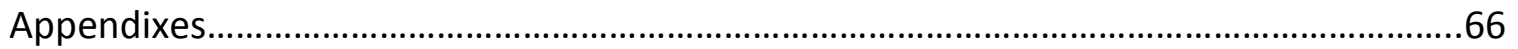


List of Tables

Table

1

2

3

4

5
Title

Page

Bivariate Correlation Matrix for Predictor

Variables and Covariates. .36

Baseline Characteristics of the Sample.

Summary of Logistic Regression Analysis for

Nicotine Withdrawal and Continuous

Abstinence at Week $3(\mathrm{~N}=266)$.

Summary of Logistic Regression Analysis for

Depressed Mood and Continuous

Abstinence at Week $3(N=266)$..

Summary of Logistic Regression Analysis for

Postcessation Self-Efficacy and Continuous

Abstinence at Week 3 ( $N=266)$. 


\section{List of Figures}

Figure

1
Title

Page

Path Coefficients for Indirect Mediation

Analysis on Week 3 Continuous Abstinence.................................43 


\section{List of Appendixes}

\begin{tabular}{|c|c|}
\hline Appendix & Title \\
\hline A & 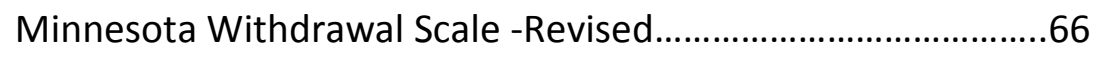 \\
\hline B & 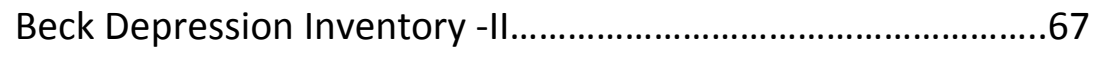 \\
\hline C & 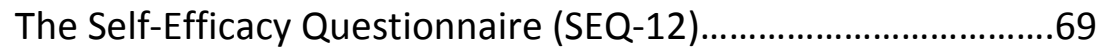 \\
\hline D & 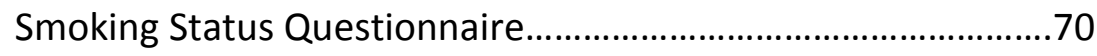 \\
\hline E & 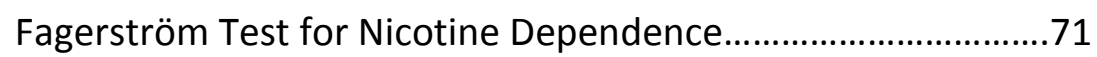 \\
\hline $\mathrm{F}$ & Baseline Demographic and Smoking History Questionnaire.....72 \\
\hline
\end{tabular}


Impact of Nicotine Withdrawal and Postcessation Self-Efficacy on

\section{Short-Term Abstinence from Smoking}

Smoking attributable diseases kill more than 39, 000 Canadians a year (Rehm et al., 2006). Worldwide, smoking is the leading preventable cause of disease and death, surpassing high blood pressure, inactivity and obesity (Mokdad, Marks, Stroup, \& Gerberding, 2004; World Health Organization [WHO], 2008). Despite the widely acknowledged health risks, $16 \%$ of Canadians are daily smokers (Health Canada, 2013). The prevalence of smoking in Canada and worldwide is reflective of the highly addictive nature of nicotine, the principal addictive component in tobacco (Sarmet \& Yoon, 2010). Both the WHO and the American Psychiatric Association (APA) recognize nicotine as an addictive substance, specifically because of its production of dependence (defined as a maladaptive pattern of substance use, leading to clinically significant impairment or distress) and, in its absence, the development of nicotine withdrawal (APA, 2013; Sarmet \& Yoon, 2010).

Many smokers want to quit and $50 \%$ of smokers in Canada have made a quit attempt in the past year (Reid, Hammond, Burkhalter, \& Ahmed, 2012). Of those smokers who try to quit on their own (i.e. without formal intervention or assistance) abstinence rates are extremely low (<2\%; Tobacco Strategy Advisory Group, 2010). The marked discomfort of nicotine withdrawal is cited by smokers as a principal reason for relapse to smoking and is a significant barrier to cessation success (Cummings, Jaen, \& Giovino, 1985; O'Connell \& Martin, 1987; West, Hajek, \& Belcher, 1989). The emergence of negative affect is a central component of nicotine withdrawal and 
arguably the most important factor as it is the only single withdrawal symptom that can reliably predict smoking cessation outcomes (Baker, Piper, McCarthy, Majeskie, \& Fiore, 2004; Hughes, 2007a). Self-efficacy in remaining smoke-free, or one's belief in their ability to resist the temptation to smoke (postcessation self-efficacy) also has been established as a significant predictor of smoking cessation outcomes (Dornelas, Sampson, Gray, Waters, \& Thompson, 2000; Haug et al., 2010; Gwaltney, Metrik, Kahler, \& Shiffman, 2009; Hendricks, Delucchi, \& Hall, 2010; Meland, Maeland, \& Laerum, 1999; Ockene et al., 2000) and may significantly counter the adverse impact of nicotine withdrawal symptoms on successful abstinence from smoking. The objectives of the current study are to evaluate the impact of nicotine withdrawal symptoms, postcessation depressed mood, and postcessation self-efficacy on abstinence.

\section{Nicotine Withdrawal}

Nicotine, a principal ingredient of tobacco smoke, is arguably the most tenaciously addictive substance available in our community; individuals exposed to tobacco on at least one occasion are more likely to become dependent (32\%) than those exposed on a single occasion to heroin (23\%), cocaine (17\%) or alcohol (15\%; Anthony, Warner, \& Kessler, 1994). Tobacco is used in a number of ways: cigarettes, cigars, pipes and chewing tobacco. Cigarettes, carefully engineered drug delivery devices, are the most efficient and widely used nicotine delivery system (Sarmet \& Yoon, 2010). Tobacco smoke carries nicotine into the lungs where it is speedily absorbed into the pulmonary circulation and arterial system and carried rapidly to the brainstem, where it binds to nicotinic cholinergic receptors (nAChRs). Nicotine activation of nAChRs, 
(principal among which are the $\alpha-4 \beta-2$ nicotinic receptors) causes the release of a variety of neurotransmitters, including dopamine, in the forebrain (Benowitz, 2008). The release of such neurotransmitters results in feelings of pleasure, reduces anxiety and stress and increases concentration, reaction time and task performance (Benowitz, $2009,2010)$. Minimal exposure to smoking results in the development of dependence and a variety of specific neuroadaptations. Thereafter, the brain requires the regular readministration of nicotine to maintain a degree of neurophysiological 'equanimity' permitting 'normal' brain function (De Biasi \& Dani, 2011; Paolini \& De Biasi, 2011). When a smoker's brain does not receive nicotine (i.e. during a quit attempt) a disruption of that neurophysiological equanimity occurs resulting in a deficiency in the release of dopamine and other neurotransmitters, leading to a state of discomfort and disequilibrium described as the 'nicotine withdrawal syndrome' (Hughes, 2007a; Paolini \& De Biasi, 2011).

Shiffman, West, and Gilbert (2004) define nicotine withdrawal as, "a syndrome of behavioural, affective, cognitive, and physiological symptoms, typically transient, emerging upon cessation or reduction of tobacco use, and causing distress or impairment" (p. 600). In general, the nicotine withdrawal syndrome is characterized by the emergence of at least four of the following symptoms: anger/irritability/frustration; anxiety; depressed mood; restlessness; difficulty concentrating; impatience; increased appetite and weight gain; insomnia; and craving for tobacco (APA, 2013; Etter, Ussher, \& Hughes, 2013; Hughes, 2007b). Symptoms of the nicotine withdrawal syndrome typically emerge within a few hours following abstinence and can persist for up to 4 
weeks or more (Hughes, 2007b). Nicotine withdrawal symptoms are rapidly reversed with a resumption of smoking and the associated rapid readministration of nicotine (Benowitz, 2008). Several validated assessment scales have been developed to measure the presence and intensity of nicotine withdrawal (Etter, 2005; Hughes \& Hatsukami, 1986; Shiffman \& Jarvik, 1976). In general, nicotine withdrawal scores represent withdrawal severity (or intensity) and/or withdrawal symptom frequency; they are expressed as either an aggregate score of multiple symptoms or as a score of an individual symptom (e.g. depression; Hughes, 2007c; Shiffman et. al, 2004).

Prevalence of Nicotine Withdrawal Symptoms

Population-based studies assessing nicotine withdrawal symptoms experienced by smokers in their lifetime, have reported prevalence (the proportion of smokers affected by nicotine withdrawal symptoms) ranging from $22 \%$ to $76 \%$ (Breslau, Kilbey, \& Andreski, 1992; Henningfield, 1995; Hughes, 2007a). This large variance in prevalence may be due to methodology: retrospective studies collecting withdrawal data are vulnerable to memory bias; do not account for baseline levels of withdrawal symptoms prior to cessation; and, sometimes fail to include validated nicotine withdrawal symptoms (Hughes, 2007a). Most importantly, studies reporting "lifetime nicotine withdrawal" cannot predict the probability of experiencing nicotine withdrawal during a specific quit attempt (Hughes, 2007a).

Two large investigations have prospectively examined the prevalence of nicotine withdrawal symptoms in smokers making unaided quit attempts. Gritz, Carr, and Marcus (1991) recruited smokers who were quitting unaided $(N=554)$ using public 
service announcements, radio and television advertisements, and posters in the community. Participants were daily smokers, ready to make a quit attempt and randomized in a 2:1 ratio to either frequent contact (FC) or infrequent contact (IC) groups. Participants in the FC group completed a 17-item nicotine withdrawal checklist on Day 1, 2 and 7 following their target quit date (TQD) and 1, 3, 6 and 12 months postTQD. On Day 1 and 2 post-TQD, participants in the FC group were asked about nicotine withdrawal symptoms that day. Thereafter, at 7 days and 1, 6 and 12 months post-TQD FC abstainers were asked over the telephone about their nicotine withdrawal in the preceding 48 hours. Participants indicated whether they had experienced any withdrawal symptoms and, if so, rated the severity of the symptoms using a 5-item Likert scale $(1=$ not at all severe to $5=$ very severe $)$. Of those participants who remained abstinent, at least 1 nicotine withdrawal symptom was reported by $87 \%$ of participants on day $1,90 \%$ of participants on day 2 and $88 \%$ of participants on Day 7 post-TQD. Prevalence of withdrawal symptoms for those quitters who remained abstinent peaked during Day 2 post-TQD, with prevalence ranging from 55\% (restlessness) to $8 \%$ (insomnia) (Gritz et al., 1991). Unfortunately, preabstinence nicotine withdrawal scores were not obtained, this analysis did not, therefore, control for the natural occurrence of these symptoms in the study sample before the cessation attempt. In addition, nicotine withdrawal scores were not collected from those participants who had relapsed to smoking at follow-up. There is evidence that excluding smokers from a nicotine withdrawal analysis biases the sample (Hughes, 2007c) based on assumptions that may not be valid i.e. those who resume smoking have lower nicotine withdrawal as a 
consequence of their return to smoking (Piasecki, Jorenby, Smith, Fiore, \& Baker, 2003b).

Hughes (1992) prospectively examined the prevalence of nicotine withdrawal in 630 smokers making a quit attempt. Smokers who were quitting on their own were recruited from the community using newspaper and radio advertisements. Potential participants were excluded if they had recently reduced cigarette consumption or were not smoking daily, as it was felt that this would impact the emergence of nicotine withdrawal symptoms during a cessation attempt. Nicotine withdrawal symptoms (Hughes, Gust, Skoog, Keenan, \& Fenwick, 1991; Hughes \& Hatsukami, 1986) and smoking status were collected at baseline (preabstinence) and at 2, 7, 14, 30, 90 and 180 days post-TQD. Prevalence, or incidence, of withdrawal symptoms was calculated as the percentage of participants who demonstrated an increase in symptom severity from baseline (precessation) at 2, 7, 14 and 30 days postcessation. Symptom severity was measured on a 4 -point scale $(0=$ none, $1=$ mild, $2=$ moderate, $3=$ severe $) ;$ an increase in symptom severity was defined as a minimum 1 unit increase from baseline score. Nicotine withdrawal scores were highest 2 days postcessation; $49 \%$ of abstainers experienced the nicotine withdrawal syndrome (Hughes, 1992) defined as the emergence of four or more nicotine withdrawal symptoms (APA, 2013). Incidence of specific withdrawal symptoms ranged from $31 \%$ (depression) to $53 \%$ (hunger); the prevalence of withdrawal symptoms decreased over time declining to precessation levels 30 days post-TQD (Hughes, 1992). 
Thus, the prevalence of validated nicotine withdrawal symptoms (Hughes, $2007 b$ ) in smokers making a quit attempt ranges from approximately $30-50 \%$; $90 \%$ of abstainers reporting at least one nicotine withdrawal symptom and $50 \%$ of abstainers experiencing nicotine withdrawal syndrome (the emergence of 4 or more symptoms) (APA, 2013; Gritz et al., 1991; Hughes, 1992). It is clear that nicotine withdrawal is a tobacco related disorder (APA, 2013) causing distress in those abstaining from tobacco and impeding successful cessation.

\section{Nicotine Withdrawal and Smoking Cessation Outcomes}

Patten and Martin (1996) conducted a literature review to examine the relationship between nicotine withdrawal and relapse to smoking. Fifteen studies prospectively measuring nicotine withdrawal and relapse were included in the review. Study samples included both "self-quitters" (individuals quitting without formal intervention) and "clinic quitters" (individuals who received a smoking cessation intervention). Eight studies reported short-term outcomes (2-12 weeks), three studies reported long-term outcomes (26-52 weeks) and four studies reported both short- and long-term outcomes.

Of the eight studies which reported short-term outcomes, only half found that the presence of withdrawal symptoms significantly predicted relapse (Covey, Glassman, \& Stetner, 1990; Norregaard, Tonnesen, \& Petersen, 1993; Robinson et al., 1992; West et al., 1989). Robinson et al. (1992) and Covey et al. (1990) both found that mean nicotine withdrawal severity score predicted relapse at Weeks 2 and 4 respectively. West et al. (1989) however found that, while depression and craving score predicted 
relapse at Week 2, mean nicotine withdrawal severity score was not related to relapse at Week 4. Norregaard et al. (1993) found that only weight gain predicted relapse $(N=$ 286; $70 \%$ female).

Only one of the three studies measuring long term outcomes of nicotine withdrawal and relapse found a significant relationship between mean nicotine withdrawal severity and relapse to smoking at 6 months (Percisco, 1992). Two studies measuring long-term outcomes did find a significant relationship between weight gain and abstinence from smoking at 6 and 12 months (Hall, Ginsberg, and Jones, 1986; Swan and Denk, 1987).

Patten and Martin (1996) concluded that the literature at that point did not appear to strongly link nicotine withdrawal symptoms to relapse to smoking but that this perhaps reflected methodological issues, (including measurement, exclusion bias and non-generalizable samples) and obstructed a clear understanding of the predictive validity of nicotine withdrawal. The majority of studies that found an association between nicotine withdrawal and relapse assessed that relationship using short term cessation outcomes (Covey et al., 1990; Gritz et al., 1991; Norregaard et al., 1993; Robinson et al., 1992; West et al., 1989). As nicotine withdrawal symptoms generally decline over the first four weeks of abstinence (Hughes, 1992), it is not surprising that nicotine withdrawal might predict relapse more consistently early in a quit attempt.

A more recent review of the nicotine withdrawal and relapse literature was completed by Hughes (2007a) who identified six additional studies that prospectively examined whether an increase in nicotine withdrawal symptoms postcessation 
predicted relapse to smoking. Three studies found that an increase in total withdrawal severity score predicted relapse (al'Absi, Hatsukami, Davis, \& Wittmers, 2004; Piasecki, Fiore, \& Baker, 1998; Piasecki, Jorenby, Smith, Fiore, \& Baker, 2003a) whereas 3 found that it did not (Hatsukami et al., 2000; Perkins et al., 1996; Strasser et al. 2005). In an observation consistent with that of Patten and Martin (1996), Hughes (2007c) attributed inconsistent findings regarding the strength of the association between nicotine withdrawal and relapse to methodological differences across the studies (e.g. timing of nicotine withdrawal assessments, variability in measurement tools). In his review of the measurement of the effects of abstinence from tobacco, Hughes (2007c) suggests that when examining the association between nicotine withdrawal and smoking cessation outcomes researchers should: collect nicotine withdrawal prospectively (vs. retrospective recall of withdrawal symptoms); conduct the study with a sample of smokers ready to quit (abstinence study vs. deprivation study); schedule study follow-up visits soon after the TQD; assess nicotine withdrawal using a validated instrument; and, collect preabstinence withdrawal scores. Controlling for preabstinence withdrawal score (while smoking) when interpreting postabstinence withdrawal will account for any variance preexisting symptoms may have on predicting abstinence (Etter et al., 2013; Hughes, 2007c).

The current study seeks, in part, to use the recommendations of Hughes (2007c) to examine whether nicotine withdrawal severity score at week one post-TQD will predict smoking cessation outcomes at week three post-TQD, while controlling for preabstinence withdrawal symptoms. As nicotine withdrawal symptoms are 
experienced by smokers up to one month post TQD it is likely the association between nicotine withdrawal and smoking cessation outcomes will be strongest early in the quit attempt (Hughes, 2007b).

In addition to total nicotine withdrawal severity, the presence of depressed mood has been shown to have a strong association with smoking cessation outcomes (Baker et al., 2004; Hughes, 2007a). Thus, it is important to assess specific components of the withdrawal syndrome.

\section{Postcessation Depressed Mood and Smoking Cessation Outcomes}

Increased negative affect is a principal component of nicotine withdrawal and is associated with poor cessation outcomes in those smokers trying to quit (al'Absi et al., 2004; Piper et al., 2011; Strasser et al., 2005). Variables related to negative affect which have been examined in relation to smoking cessation outcomes include a history of depression, and both precessation and postcessation depressed mood (Cinciripini et al., 2003; Hitsman, Borrelli, McChargue, Spring, \& Niaura, 2003). Depressed mood is a nicotine withdrawal symptom that consistently predicts relapse to smoking in both pharmacological and behavioural treatment studies (Etter \& Hughes, 2006; Etter et al., 2013; Hughes, 1992; Hughes, 2007a; Killen, Fortmann, Schatzberg, Hawyard, \& Varady, 2003; Pomerleau, Namenek-Brouwer, \& Pomerleau, 2001; Swan, Ward, \& Jack, 1996). Pomerleau et al. (2001) previously explored the association between the emergence of depressed mood and relapse during the early stages of a quit attempt in a sample of depressed and nondepressed women. Smokers $(N=99 ; \geq 15$ cigarettes per day) were assessed using a modified version of the Center for Epidemiological Studies - 
Depression (CES-D) scale, and classified as either depressed (CES-D $\geq 16 ; n=27$ ) or nondepressed (CES-D < 16; $n=72$ ). Participants were assessed at baseline (quit date) and at Week 1 and 2 post-TQD. All participants used a 21-mg nicotine replacement therapy (NRT) patch for the first 2 weeks and received standard behavioural counselling. Participants kept daily diaries to document their smoking status and withdrawal symptoms. An expired carbon monoxide (CO) measure was taken at the Week 1 and 2 counselling visit to confirm self-reported abstinence.

There were no significant differences between depressed and nondepressed women at baseline on age, race, education, body mass index (BMI), nicotine dependence and cigarettes smoked per day. Groups did not vary on missing data; missing smoking status for any given day was coded as smoked. Pomerleau et al. (2001) found that women in the depressed group were more likely to lapse on the first day of the quit attempt and smoked more days during the first week post-TQD compared to the nondepressed women. Depressed women also relapsed to smoking earlier than did nondepressed women.

To examine the impact of depressed mood emerging after abstinence, Pomerleau et al. (2001) subtracted the mean baseline depression ratings from the mean depression rating on the first day of abstinence and correlated it with time to first lapse in both depressed and nondepressed women. A significant correlation was noted $r=-$ $.32(p<.01)$ indicating that increases in depressed mood immediately after quitting, in both depressed and nondepressed women, resulted in an earlier lapse. This finding is consistent with that of Hughes (1992) who found that those quitters whose depression 
scores had increased from quit date to 2 days post-TQD were more likely to relapse than those whose depression scores remained the same or decreased.

Etter and Hughes (2006) compared the psychometric properties of three smoking cessation withdrawal scales: the Minnesota Withdrawal Form (MWF; Hughes \& Hatsukami, 1986) the Wisconsin Smoking Withdrawal Scale (WWS; Welsch et al., 1999) and the Cigarette Withdrawal Scale (CWS) and evaluated their ability to predict abstinence at Days 14 and 42 post abstinence. The three scales differ in length and content but all reflect DSM criteria for nicotine withdrawal. The CWS includes 21 items and six subscales, items are answered on a 5- point Likert scale (totally agree to totally disagree); this withdrawal scale was originally developed in French. The WWS includes 28 items and seven subscales, items are answered on a 5-point Likert scale (strongly agree to strongly disagree). The MWS included 8 items answered on a 5-point Likert scale (none to severe). All three scales ask participants to rate mood in the previous 24 hours to prevent potential bias associated with labelling the scales nicotine withdrawal (Etter \& Hughes, 2006).

Participants (mean age $=39 ; 67 \%$ female) were recruited $(N=4,644)$ using an internet cohort from the United Sates (50\%), Canada (12\%), United Kingdom (8\%), Denmark (8\%), France (3\%) Switzerland (3\%) and other countries (16\%; Etter \& Hughes, 2006). Recruitment emails were sent to smokers and former smokers who had participated in an online smoking cessation program or a website for health information. Participants were invited to answer the questionnaires (all scales were provided in English) and report smoking status a second time, 14 days after baseline. 
Participants were subsequently invited by email to participate in a retest 42 days post baseline. Smoking status was obtained by asking: "did you smoke tobacco during the past 7 days (even one puff of a cigarette, cigar, pipe etc)". The Day 14 and 42 retest surveys were answered by $n=1,309$ and $n=1,431$ participants respectively.

At baseline the sample included 2,221 former smokers (48\%), 1,730 daily smokers (37\%), 288 nondaily smokers (6\%), 318 never smokers (7\%) and 87 people (2\%) with unknown smoking status (Etter \& Hughes, 2006). Daily smokers smoked an average of 20 cigarettes per day $(S D=12)$ at baseline. Fifty percent of the former smokers had quit smoking only in the previous 60 days (Etter \& Hughes, 2006). The authors examined the predictive validity of the three scales and individual symptoms within the three scales. The primary hypothesis was that lower nicotine withdrawal ratings would predict abstinence.

More former smokers answered the Day 42 retest survey (40\%) compared to daily smokers (24\%). Among the 316 former smokers who had quit 0-31 days before baseline and were still abstinent at baseline, 107 (34\%) had relapsed by day 42 followup; relapse was not predicted by any nicotine withdrawal symptoms. When the analysis was restricted to former smokers who had quit smoking 0-10 days before baseline $(N=$ 150), Day 42 relapse was consistently predicted by depressed mood across the three withdrawal scales; depression (CWS, OR $=1.48, p=.021$ ) sadness (WWS, OR $=1.62, p=$ $.010)$ and depressed mood (MWF, OR $=1.41, p=.022)$. The only other nicotine withdrawal items that predicted relapse at Day 42 retest, across all three scales, were 
irritability (CWS), anger (WWS), anxiety (MWF) and craving (MWF; Etter \& Hughes, 2006).

Of those participants who were daily smokers at baseline, 34 had quit smoking at Day 14 retest and took part in the Day 42 retest (Etter \& Hughes, 2006). Change scores were calculated for symptoms from baseline to 14 day retest to examine whether increases in nicotine withdrawal directly prior to quitting would predict relapse. Etter and Hughes (2006) found that increases in depressed mood from baseline to the Day 14 retest (as measured by the MWF) predicted relapse at Day $42(\mathrm{OR}=2.62, \mathrm{p}<.05)$. Craving (measured by WWS and MWF) and difficulty concentrating (WWS) also predicted relapse to smoking at the Day 42 day retest.

The current study seeks, in part, to build on the above research and examine further the relationship between postcessation depressed mood and smoking cessation outcomes in a sample of smokers not currently suffering from depression. More specifically, depressed mood score at week one post-TQD will predict smoking cessation outcomes at week three post-TQD, while controlling for baseline (preabstinence) levels of depressed mood.

\section{Self-Efficacy and Smoking Cessation Outcomes}

Self-efficacy (Bandura, 1977) in relation to smoking cessation can be characterized in two ways: confidence in quitting smoking and in remaining smoke-free; or, one's ability to resist the temptation to smoke during abstinence (Morrell, Skarbek, \& Cohen, 2011). The relationship between self-efficacy and abstinence has been studied extensively. A literature review by Gwaltney et al. (2009) identified 253 articles 
published between 1966 and 2005 addressing self-efficacy, self-confidence, smoking, relapse and abstinence. The empirical evidence supports the theoretical relationship between self-efficacy and abstinence; high self-efficacy increases the probability of abstaining from smoking and lower self-efficacy increases the probability of relapse (Dornelas et al., 2000; Haug et al., 2010; Gwaltney et al., 2009; Hendricks et al., 2010; Meland et al., 1999; Ockene et al., 2000).

Gwaltney et al. (2009) conducted a meta-analysis of the literature examining self-efficacy and smoking cessation to determine the magnitude of this relationship and, thus, its theoretical and clinical importance. Studies measuring self-efficacy before a quit attempt (i.e. confidence in quitting smoking, prequit group) were analyzed separately from those that measured self-efficacy after a quit attempt (i.e. confidence in remaining smoke-free, postquit group). Recognizing the variability in smoking cessation study designs, the authors considered how closely in time self-efficacy was measured in relation to the outcome assessment (smoker or non-smoker) as perceived self-efficacy may change over time (Gwaltney, Shiffman, Balabanis, \& Paty, 2005). Overall, the authors hypothesized that those who remain abstinent will have had higher baseline self-efficacy than those who relapsed to smoking or continued to smoke.

Fifty-four studies were included in the analysis (Gwaltney et al., 2009). Studies were included if they had a prospective design and were published in a peer reviewed journal. Studies were excluded if they did not explicitly measure self-efficacy or the authors used the difference between an individual's self-efficacy scores measured at different time points (i.e. change scores) to predict smoking cessation outcomes in their 
analysis. A standardized mean difference statistic $d$, was used to measure effect size between baseline self-efficacy scores in those participants who were, or were not, smoking at follow-up. A negative $d$ statistic indicated higher baseline self-efficacy scores for those participants who were not smoking at study follow-up (Gwaltney et al. 2009). The results of Gwaltney et al. (2009) indicated that self-efficacy in the postquit group (i.e. self-efficacy measured after the quit attempt) had a statistically stronger association $(d=-.47)$ with smoking status than did self-efficacy in the prequit group ( $d=$ $-.21)$, where an effect size score of $d=-.47$ in the postquit group indicates non-smokers scored .47 standard deviations units higher on baseline self-efficacy compared to smokers. This finding demonstrates that self-efficacy measured after the quit attempt is a stronger predictor of smoking status at follow-up than self-efficacy measured before a quit attempt.

Within the prequit group, the relationship between self-efficacy and outcome was $d=-.12$, where non-smokers self-efficacy scores were .12 standard deviations higher than smokers (Gwaltney et al., 2009). Effect size did not significantly differ with length of time the prequit group self-efficacy measurement was taken from the outcome assessment. Within the postquit group, the association between self-efficacy and smoking status was much stronger $d=-.79$ (Gwaltney et al., 2009). In addition, the relationship between self-efficacy and smoking status was influenced by length of time between the self-efficacy measurement and the outcome assessment $d=-.001(p<$ .001). This can be interpreted as an effect size decrease of .001 with each additional day between self-efficacy measurement and outcome assessment. Thus, the relationship 
between self-efficacy and smoking status, when measured postquit attempt, diminishes as the length of time between the self-efficacy measurement and outcome assessment increases.

Overall, the meta-analysis did support the hypothesis that higher self-efficacy leads to a greater likelihood of remaining abstinent from smoking, or conversely, that lower self-efficacy leads to a higher probability of relapse to smoking (Gwaltney et al., 2009). In addition to this finding Gwaltney et al. (2009) also noted measuring selfefficacy postcessation and shorter time intervals between self-efficacy measurement and outcome assessment strengthen the association between self-efficacy and smoking status. With this in mind, the current study will use postcessation self-efficacy scores at week one post-TQD to predict smoking cessation outcomes at week three.

Since the Gwaltney et al. (2009) meta-analysis, researchers have continued to investigate the relationship between postcessation self-efficacy and smoking cessation outcomes including: time varying trajectories of self-efficacy post-quit attempt (Prenger et al., 2013); increases in self-efficacy post-quit attempt (Schnoll et al., 2011); the moderating effect of 'type' of quitter (i.e. those who quit on their own versus those who seek smoking cessation services) on self-efficacy (Elfeddali, Bolman, Candel, Wiers \& De Vries, 2012); and, self-efficacy as a mediator of smoking behavior i.e. "the process by which some variables exert influences on others through intervening or mediator variables" (Preacher \& Hayes, 2008, p. 879). Berndt et al. (2013) tested baseline selfefficacy as a mediator of the effect of craving on abstinence; Cinciripini et al., (2003) evaluated the mediation effect of postcessation self-efficacy on precessation depressed 
mood and smoking abstinence; both studies found self-efficacy to be a mediator of smoking cessation behaviour. No study to date has tested postcessation self-efficacy as a mediator of the effect of nicotine withdrawal on smoking cessation outcomes; the current study will specifically test this hypothesis.

Postcessation Self-Efficacy and Symptoms of Nicotine Withdrawal

Bandura's self-efficacy theory (1977) posits that self efficacy, the measure of one's own perceived capability to complete tasks and manage situations, is affected by four factors: mastery of experience; vicarious learning; social persuasion; and, physiological factors. Mastery of experience is related to task performance and reflects the degree to which successful performance of a task leads to increased self-efficacy and unsuccessful performance of a task decreases self-efficacy. Vicarious learning occurs by observing individuals similar to oneself successfully complete a task. Social persuasion is feedback received from others typically in the form of verbal encouragement, which increases self-efficacy, or verbal discouragement, which decreases self-efficacy. Finally, physiological factors that follow a behaviour provide feedback to the individual undertaking the behaviour which has a subsequent effect on self-perceptions of ability.

Nicotine withdrawal is characterized as a principal negative reinforcer whose presence perpetuates the cycle of tobacco addiction (Baker et al., 2004; Eissenberg, 2004; Hughes, 2007a). Nicotine, as previously noted, causes the release of a variety of neurotransmitters, including dopamine, in the forebrain (Benowitz, 2008). During a quit attempt a smoker's brain does not receive nicotine which leads to disruption of 
neurophysiological equanimity resulting in a deficiency in the release of dopamine and other neurotransmitters, leading to an array of symptoms such as anger/irritability/frustration; anxiety; depressed mood; restlessness; difficulty concentrating; impatience; increased appetite and weight gain; insomnia; and craving for tobacco (APA, 2013; Etter, Ussher, \& Hughes, 2013; Hughes, 2007b). According to self-efficacy theory (Bandura, 1997) negative physical states can lead to a decrease in self-efficacy that undermines one's ability to maintain health promoting behaviours such as abstinence from smoking. This decrease in self-efficacy as a result of the negative physical states experienced as withdrawal symptoms may mediate the effect of nicotine withdrawal on relapse to smoking wherein the negative physiological feedback that follows abstinence (nicotine withdrawal) will lower self-perceptions of ability to remain smoke-free (postcessation self-efficacy) and lead to relapse. Conversely, those with lower levels of nicotine withdrawal will be more likely to be smoke-free at Week 3 post-TQD and this relationship will be mediated by higher levels of Week 1 postcessation self-efficacy.

One study has explicitly examined the association between self-efficacy and nicotine withdrawal (Morrell et al., 2011) while Cinciripini et al. (2003) evaluated postcessation self-efficacy as a mediator of smoking behaviour. Morrell et al. (2011) recruited smokers ( $>16$ cigarettes per day), at least 18 years of age and who scored $\geq 4$ on the Fagerström Test for Nicotine Dependence (FTND). A score of $\geq 4$ on the FTND indicates a moderate to high level of nicotine dependence (Heatherton, Kozlowski, Frecker, \& Fagerström, 1991). Smokers in this study $(N=21)$ did not have to be ready to 
quit and their desire to quit was not evaluated. The 21 participants had a mean age of 24 years; $23.8 \%$ were female. All participants were daily smokers and had smoked for an average of 6.9 years. The average nicotine dependence score at baseline was 5.1, reflecting moderate nicotine dependence (Heatherton et al., 1991). The MWS was used to assess the severity of nicotine withdrawal (Hughes et al., 2003; Hughes \& Hatsukami, 1986); self-efficacy was measured using the Self-Efficacy/Temptations Scale (SETS) (Velicer, Diclemente, Rossi, \& Prochaska, 1990). After baseline demographics and smoking history were recorded, participants underwent the deprivation phase in which they were asked to abstain from smoking for 48 consecutive hours; participants returned to the lab 24 and 48 hours post abstinence. Exhaled CO levels were measured at each follow-up in order to validate the self-reported abstinence. A CO reading of $>10$ ppm was considered indicative that the participant had relapsed to smoking and a time was scheduled to repeat the 48 hour deprivation phase. Self-efficacy and nicotine withdrawal severity were measured following 24 and 48 hours of abstinence.

Morrell et al. (2011) hypothesized that nicotine withdrawal severity would predict the level of self-efficacy, i.e. high levels of withdrawal severity would predict low self-efficacy and low levels of withdrawal severity would predict high self-efficacy. Alternatively the authors hypothesized that self-efficacy would predict nicotine withdrawal, where high self-efficacy would predict low nicotine withdrawal severity and low self-efficacy would predict increased nicotine withdrawal severity (Morrell et al., 2011). The authors used linear regression analysis to test their hypotheses. 
Three separate analyses were undertaken to test each hypothesis predicting nicotine withdrawal severity or self-efficacy at three time points; baseline to 24 hours abstinent, baseline to 48 hours abstinent and 24 hours to 48 hours abstinent (Morrell et al., 2011). The results of the six linear regressions revealed no significant associations between the level of self-efficacy and nicotine withdrawal severity or, alternatively, the level of nicotine withdrawal and self-efficacy. Self-efficacy measured after 24 hours of abstinence, controlling for previous cigarette consumption, depression, and anxiety, showed a nonsignificant trend toward predicting nicotine withdrawal severity at 48 hours of abstinence $(p=.052)$

The Morrell et al. (2011) study has limitations. The experiences of smokers from a "college" sample (mean age of 24 years) may not be generalizable to smokers in the community. In addition, nicotine withdrawal and self-efficacy scores associated with deprivation from smoking may not be representative for smokers who are ready to quit. The current study seeks to explore this relationship further in a sample of 'real world' smokers recruited from the community who are ready to quit.

Cinciripini et al. (2003) explored self-efficacy as a factor that may influence the relationship between precessation depressed mood and relapse to smoking. It was hypothesized that baseline depressed mood would have an inverse relationship to six month abstinence and that the effect would be mediated by postcessation self-efficacy. Smokers ( $\geq 15$ cigarettes per day), who had not had a diagnosis of major depression or treatment with antidepressants within the past year, were recruited $(N=121)$ from the community and randomized to either behaviour therapy alone (BT) or behavioural 
therapy plus transdermal nicotine patch treatment (BTP). Participants in both groups received nine weekly group counselling sessions focusing on coping skills while the BTP group received an additional 8-12 weeks of nicotine patch treatment. A quit date was set within three weeks of the baseline visit. Precessation depressed mood (Profile of Mood States (POMS) Depression Scale), nicotine withdrawal, self-efficacy, smoking history, nicotine dependence and demographics measures were assessed at baseline, on the quit date and at Weeks 1, 2, 4, 8 and 26 post-TQD. A participant was classified as smoke-free if they reported not smoking in the 7 days prior to the follow-up assessment and had an expired $\mathrm{CO}$ of $<8 \mathrm{ppm}$. Participants with missing smoking status data at follow-up were classified as smokers (Cinciripini et al., 2003).

Participants were on average 43.1 years of age $(S D= \pm 12.3), 70 \%$ female and smoked, on average, 25.1 (SD = \pm 11.9 ) cigarettes per day (Cinciripini et al., 2003). Demographic (gender, age, education possible past history of depression) and smoking (nicotine dependence, previous quit attempts, baseline cigarettes per day) variables were evaluated in order to assess any relationship with precessation depressed mood scores. POMS scores were higher among those who had a possible history of depression (14\%).

Precessation depressed mood was found to significantly predict 6 month relapse, when controlling for treatment group and possible history of depression (OR = $.898,95 \% \mathrm{Cl}=.829-.974)$ indicating that higher levels of precessation depressed mood predicted relapse at 26 week follow-up (Cinciripini et al., 2003). Next, Cinciripini et al. (2003) followed the Baron and Kenny (1986) procedure to evaluate whether self- 
efficacy, coping behaviour, urges to smoke, and nicotine withdrawal symptoms at Weeks 1, 2, 4 or 8 mediated the effect on precessation depressed mood on 6 month abstinence.

The strongest mediator of the effects of precessation depressed mood on abstinence was postcessation self-efficacy accounting for $32 \%, 38 \%$ and $48 \%$ of the effect of depressed mood on abstinence, at Week 2, 4 and 8 respectively (Cinciripini et al., 2003). Self-efficacy at Week 1 post-TQD was not found to mediate the effects of depressed mood on 6 month abstinence. Of those variables tested in this investigation, self-efficacy was the only one that successfully mediated the effect of precessation depressed mood on six month abstinence.

Although the current study uses postcessation depressed mood to predict relapse, the findings of Cinciripini et al. (2003) indicate that there is evidence postcessation self-efficacy mediates the relationship between aversive emotional states and smoking cessation outcomes.

Objectives of the Current Study

In summary, the current literature suggests that the emergence of nicotine withdrawal symptoms is associated with an adverse effect on smoking cessation outcomes, and that depressed mood, as an individual withdrawal symptom, has consistently shown an association with relapse to smoking. Self-efficacy to remain smoke-free has a positive association with sustained abstinence. Despite the large body of literature examining these variables, gaps remain in our understanding of how selfefficacy interacts with the emergence of nicotine withdrawal symptoms, and specifically 
depressed mood. If nicotine withdrawal symptoms lead to lower levels of self-efficacy during a quit attempt, then it is possible that postcessation self-efficacy plays a meditational role in the relationship between nicotine withdrawal symptoms and smoking cessation outcomes however, to date, this hypothesis has not been tested. Fundamentally, the purpose of the current study is to test the mediational role of postcessation self-efficacy early in a quit attempt in a sample of smokers, recruited from the community, who are ready to quit. The identification of behavioural processes, such as self-efficacy, which may influence the effect of nicotine withdrawal and depressed mood on abstinence early in a quit attempt might enable the development of clinical interventions that more specifically address those factors that have the greatest influence on cessation success during a period when the probability of relapse is the highest (Piasecki, 2006).

\section{Hypotheses}

Hypothesis I. Lower nicotine withdrawal severity score at Week 1 post-TQD will predict continuous abstinence at Week 3 post-TQD, after controlling for preabstinence nicotine withdrawal score.

Hypothesis II. Lower depressed mood score at Week 1 post-TQD will predict continuous abstinence at Week 3 post-TQD, after controlling for preabstinence depressed mood score.

Hypothesis III. Higher postcessation self-efficacy score at Week 1 post-TQD will predict continuous abstinence at Week 3 . 
Hypothesis IV. The hypothesized causal relationship in hypotheses I and II will be mediated by postcessation self-efficacy scores at week one.

Method

\section{Study Design}

To test the study hypotheses, secondary analyses was performed using data from a 52-week, parallel, two group, open label, randomized control trial (RCT). Participants were enrolled in a randomized smoking cessation trial comparing 10 weeks of standard transdermal nicotine patch to 10 weeks of titrated transdermal nicotine patch. As randomization group may have a direct effect on the experience of nicotine withdrawal symptoms ${ }^{1}$, the treatment arm was included in all analyses to control for this variable as a potential confounder.

\section{Participants}

Participants $(N=266)$ were daily smokers from the Ottawa-Gatineau area recruited by various means: radio and newspaper recruitment campaigns; study advertisements in the community; referral from community physicians and dentists; and from the Quit Smoking Program information sessions held at the University of Ottawa Heart Institute (UOHI). Advertisements invited current smokers who were ready to quit to participate in a study and receive cost-free quit smoking medications.

To be eligible for the study participants had to be adults (over the age of 18), a current smoker ( $\geq 10$ cigarettes per day), willing to set a quit date within 30 days

\footnotetext{
${ }^{1}$ Participants were randomized to a treatment of standard dose NRT, which treats the symptoms of nicotine withdrawal, versus titrated dose NRT, a higher dose of NRT which should provide even greater relief from nicotine withdrawal symptoms.
} 
following a baseline assessment, motivated to quit and willing to return to the study centre for counselling and follow-up visits. Individuals were excluded if they: had made a quit attempt, or used smoking cessation medication for $>72$ consecutive hours in the previous month; had contraindications to the use of nicotine replacement therapy (e.g. allergy to adhesive); were currently suffering from depression or had been diagnosed with depression or treated with an antidepressant in the previous 12 months; had a past or present history of psychosis, panic disorder or bipolar disorder; had demonstrated drug or alcohol abuse or dependence within the last year; or, were pregnant or planning to become pregnant during the course of the study. The mean age of participants was 48 years $(S D=11.11)$, approximately two-thirds were male $(63.5 \%)$ and most participants were Caucasian (90\%).

Procedure

Smokers who met screening criteria during a telephone interview were provided with an overview of the study and invited to the UOHI to complete a baseline visit. At the baseline visit, smokers were re-assessed for eligibility, described the study procedures in detail, and completed a consent form followed by a questionnaire package that included baseline measures of self-efficacy, nicotine withdrawal, depressed mood, nicotine dependence, smoking history and demographics. In addition, each participant provided their medical history, a urine sample and measures of height and weight. Subsequently participants were randomly assigned to one of two treatment conditions: 10 weeks of standard therapy NRT or 10 weeks of titrated NRT. Following randomization, participants attended a group counselling session where they 
were given instructions on appropriate use of the patch, setting a quit date, preparing for their quit date and a discussion regarding barriers and facilitators of quitting smoking. At the end of the baseline visit, participants set their quit date and study follow-up visits were scheduled for at Weeks 1, 3, 5, 8, 10, 26 and 52, post-TQD. The NRT medication was initiated on the first day of their quit attempt and was administered up to Week 10 (end of treatment). At the Weeks 1, 3, 5, 8 and 10 followup visits, participants received one-to-one sessions with a trained smoking cessation counsellor that focused on a practical counselling (Fiore et al., 2008). Practical counselling includes identifying danger situations for relapse (events, internal states or activities that increase the risk of relapse), developing coping skills to deal with danger situations and providing basic information about successful quitting, nicotine withdrawal and proper use of NRT. The majority of participants (88\%) received smoking cessation counselling from the same counsellor for all of their one-to-one sessions. Measures of self-efficacy, depressed mood, nicotine withdrawal, use of other cessation resources and smoking status were collected at Weeks 1, 3, 5, 8, 10, 26 and 52. The UOHI institutional ethics review board approved the study protocol and all participants provided written informed consent before completing study procedures.

As the focus of the current analyses is to explore the relationship between nicotine withdrawal, self-efficacy and smoking outcomes early in the quit attempt, only data collected at time of enrolment (baseline) and at Weeks 1 and 3 post-TQD was analyzed. 


\section{Measurements}

Nicotine withdrawal. Nicotine withdrawal was measured by the Minnesota Nicotine Withdrawal Scale (MWS-R; Appendix A; Etter et al., 2013; Hughes \& Hatsukami, 1986; Hughes, 2007b) at baseline (precessation) and Weeks 1 and 3 post-TQD. The MWS-R is a 15-item self-report questionnaire which asks participants to rate the degree to which they experienced withdrawal symptoms in the previous 24 hours on a scale of 0 (none) to four (severe) in nine validated areas: angry/irritable/frustrated; anxious/nervous; depressed mood/sad; desire or craving to smoke; difficulty concentrating; increased appetite/hungry/weight gain; insomnia/sleeping problems/awakening at night; or, restless and impatient (Hughes, 2007c) and six items which may possibly be related: constipation; dizziness; coughing; dreaming/nightmares; nausea; or, sore throat (Hughes, 2007c). The MWS-R is either summed or averaged into a total nicotine withdrawal severity score (Patten \& Martin, 1996). The MWS-R (15 items) was administered to participants in the study however, for the purposes of the study, only the first nine validated items (MWS) will be used to calculate an average nicotine withdrawal score. The MWS (9 items) has demonstrated internal consistency ( $\alpha=0.85$;Etter $\&$ Hughes, 2006). Test-retest correlation for the MWS total score is 0.71 (Etter \& Hughes, 2006). The MWS is one of the most frequently used measures of nicotine withdrawal (Hughes, 2007c; Piasecki et al., 2003b; Shiffman et al., 2004); and content validity has been established with the DSM-V (APA, 2013).

Depressed mood. The Beck Depression Inventory-II (Appendix B; Beck, Steer, \& Brown, 1996) was used to assess the intensity of depressed mood. This 21 -item scale is 
a widely used, psychometrically sound, self-administered questionnaire. Its internal consistency in a normative sample is high ( $\alpha=.86$; Beck et al., 1996) and content validity has been established with the DSM-IV (APA, 2000). A recent systematic review of the utility of the BDI-II in detecting depression in medical settings (Wang \& Gorenstein, 2013) found that internal consistency was satisfactory, with Cronbach's $\alpha$ ranging from 0.84-0.94, and that the content validity, when compared to other widely used constructs to measure depression (i.e. CES-D, Hospital Anxiety and Depression Scale), was adequate ranging from $r=0.62$ to $r=0.81$. A total score is calculated by summing the participant's responses to all items. Scores from 0-13 indicate minimal depression, 14-19 indicate mild depression, 20-28 indicate moderate depression, and 29-63 indicate severe depression. Aubin (2009) recommended the use of the BDI for monitoring the emergence of depressed mood in smokers making a quit attempt.

Self-efficacy. The Self-Efficacy Questionnaire (SEQ-12) (Appendix C) was used to measure smoking self-efficacy, the confidence in one's ability to abstain from smoking (Etter, Bergman, Humair, \& Perneger, 2000). The 12-item questionnaire asks participants to indicate on a 5-point scale whether they could refrain from smoking in various high risk situations from 1 (not sure at all) to 5 (absolutely sure). Six items on the scale represent internal stimuli (e.g. when I feel nervous, when I feel angry) and six items represent external stimuli (e.g. when I'm having coffee or tea, after a meal). The SEQ-12 has high internal consistency for both the internal stimuli ( $\alpha=0.95$ ) and external stimuli ( $\alpha=0.94)$ composite subscales. Test-retest correlation coefficients were also high, 0.95 and 0.93 for the internal and external stimuli composite scales respectively 
(Etter et al., 2000). The SEQ-12 was reviewed for content validity, and Etter et al. (2000) determined that all categories of high risk situations identified in qualitative data were represented in the scale (Etter et al., 2000).

Smoking status. Continuous abstinence was measured at Week 3 post-TQD. Continuous abstinence was defined as a self-report of not smoking more than 5 cigarettes from the TQD to the follow-up appointment (West, Hajek, Stead, \& Stapleton, 2005) with an expired CO level of < 5 ppm (Perkins, Karelitz, \& Jao, 2013; Appendix D). Biochemical verification of smoking status is critical as treatment outcomes based on a self-report of nonsmoking have been found to be significantly different than treatment outcomes following a biochemical confirmation of nonsmoking $(p<0.05$; Benowitz et al., 2002). CO level was measured with a CO monitor which has been determined by the Society for Research on Nicotine and Tobacco (SRNT) Subcommittee on Biochemical verification (Benowitz et al., 2002) to be a sensitive and reliable instrument. The sensitivity and specificity with which expired $\mathrm{CO}$ can distinguish a smoker from a nonsmoker with a cutoff of $<5 \mathrm{ppm}$ is $83 \%$ and $87 \%$, respectively, with a false positive rate of 17\% (Perkins et al., 2013).

Nicotine dependence. Nicotine dependence at baseline was measured using the Fagerström Test for Nicotine Dependence (Appendix E; Heatherton et al., 1991). This brief 6-item, self-report questionnaire can yield a total score of up to 10 and classifies smokers as very low dependence (score 0-2), low dependence (score 3-4), moderate dependence (score 5), high dependence (score 6-7) and very high dependence (score 810). The FTND has been found to have good test-retest reliability ( $\alpha=0.88$; Pomerleau, 
Carton, Lutzke, Flesslan, \& Pomerleau, 1994). Nicotine dependence has been established as a predictor of smoking cessation outcomes (Berndt et al., 2013; Schnoll et al., 2011) and was included in the analyses as a covariate.

Demographics and smoking history. Participants' demographic profile included age, gender, education, marital and employment status and was assembled the time of enrolment. A standard measure was used to collect smoking related variables at baseline including: number of cigarettes smoked daily; age at time of smoking first cigarette; number of years smoked; number of quit attempts in the previous year ( $>24$ hours); previous use of smoking cessation medications; and exposure to smoking in the home and workplace (Appendix F).

Results

\section{Summary of variables}

Baseline descriptive variables include demographic and smoking history. Baseline covariates include nicotine dependence, as measured by the Fagerström Test for Nicotine Dependence (Heatherton et al., 1991), and randomization group. Additional covariates include nicotine withdrawal score at baseline (Hypothesis I) and depressed mood score at baseline (Hypothesis II). Predictor variables include Week 1 nicotine withdrawal score (Hypothesis I), Week 1 depressed mood score (Hypothesis II) and Week 1 postcessation self-efficacy score (Hypothesis III). The outcome variable for all hypotheses is smoking status at Week 3 (smoker/non-smoker). 


\section{Data screening}

Originally there were 303 participants in the study; however, the first 37

participants to enroll were excluded from the analysis as changes in the protocol during the time of their enrollment were deemed potential confounds to the current analysis. These changes to the protocol included; addition of nicotine withdrawal measures at baseline, changes to the baseline counseling session and refinement of the eligibility criteria. Additionally, the first 37 participants to enroll in the study received counseling from various smoking cessation counselors, whereas the remaining 266 participants received all six counseling sessions from the same counselor. To limit variability related to study procedures and intervention delivery, the first 37 participants enrolled were removed from the analyses resulting in a final sample size of $N=266$.

Data were examined for data entry errors and common parametric analyses (frequency distributions, range, mean, standard deviation) were conducted using Statistical Package for the Social Sciences (SPSS) version 22. Normality of the Week 1 predictor variables and baseline covariates were visually assessed by examining boxplots, stem and leaf plots, Q-Q Plots, histogram graphs, skewness and kurtosis. The data for all three variables were not normally distributed at both baseline and Week 1 . The assumption of normality does not need to be met when performing logistic regression analyses (Tabachnick \& Fidell, 2007).

Missing data. At baseline, the range of missing data for sample baseline demographics and smoking history variables ranged from $0.03 \%$ ( 1 participant) to $3.3 \%$ (9 participants). None of the participants were missing depressed mood score at 
baseline, however 14 participants (5.3\%) were missing baseline nicotine withdrawal score. Thirty-three participants (12.4\%) were lost to follow-up at the Week 1 study visit. The range of missing data at Week 1 was 12.4\% (nicotine withdrawal at Week 1), 12.8\% (postcessation self-efficacy), and 14.3\% (depressed mood at Week 1).

At Week 3, participants lost to follow-up, or attrition rate, was $18 \%$ accounting for the missing data on the outcome variable. According to Schafer and Graham (2002), when missing data arises due to lost to follow-up or drop out, missing at random (MAR) is met if missing data depends on responses prior to attrition whereas missing not at random (MNAR) indicates that missing responses are a result of unknown responses. To determine whether missingness on the outcome variable (Week 3 smoking status) could be accounted for by variables prior to attrition, a dummy variable was constructed with two groups, cases that were missing values on the outcome variable and cases that were not missing values on the outcome variable. Independent sample $t$-tests were conducted to test for mean difference in baseline and Week 1 variables for those missing and not missing values on the outcome variable (Tabachnick \& Fidell, 2007). Analyses revealed that participants with missing outcome data at Week 3 were younger in age $(t(264)=2.24, p=.03)$, had higher nicotine dependence scores at baseline $(t$ $(256)=-2.14, p=.04)$, had higher nicotine withdrawal scores at baseline $(t(250)=-2.22$, $p=.03)$ and experienced increased nicotine withdrawal severity at Week $1(t(231)=-$ 2.89, $p=.004)$. As age, nicotine dependence and nicotine withdrawal at both baseline and Week 1 can explain missing on the outcome variable, the data can be considered MAR (Schafer \& Graham, 2002; Tabachnick \& Fidell, 2007). As the data are determined 
to be MAR and contains wave nonresponse (missing data due to attrition), Schafer and Graham (2002) suggest using a multiple imputations approach to minimize the loss of data. The current analysis generated 15 imputed datasets for analyses of main effects.

Outliers. Week 1 predictor variables and baseline covariates were transformed into $z$ scores and screened for univariate outliers. Univariate outliers were defined as being more than three standard deviations from the mean, characterized by a standardized score greater than +/- 3.29 (Tabachnick \& Fidell, 2007). Three univariate outliers were found for depressed mood at Week 1 . No other univariate outliers were identified.

To further test the impact of outliers, the data were screened for multivariate outliers using Cook's distance, DFBeta's and standardized residuals to determine if there were any outlying cases that had undue influence on the results of the analyses (Tabachnick \& Fidell, 2007). To assess the influence of an individual case (i.e. measure of the change in the regression coefficient if a case were deleted from the model), Cook's distance and DFBeta's were calculated. There were no values greater than one, on either Cook's Distance scores of the standardized DFBeta's, indicating that there are no unusually high cases having an influential effect on the model. In addition standardized residuals were calculated to identify cases for which the model fits poorly. There were no standardized residual values outside $+/-3$ revealing no critical multivariate outliers (Tabachnick \& Fidell, 2007).

In summary, three cases with $z$ scores higher than $z=3.29$ on Week 1 depressed mood were found to be univariate outliers however, as Cook's distance, DFBeta's and 
standardized residual scores did not identify any multivariate outliers, the three univariate outliers were retained in the analysis.

Multicollinearity. Multicollinearity of predictor variables and covariates was assessed using bivariate correlations. These correlations are displayed in Table 1. Depressed mood at baseline was moderately associated with depressed mood at Week $1(r(226)=.41, p<.001)$; this was expected as the reported BDI-II retest correlation is $r$ $=.93$ (Beck et al., 1996). Nicotine withdrawal and depressed mood were moderately correlated at both baseline $(r(250)=.55, p<.001)$ and Week $1(r(226)=.53, p<.001)$. Due to the association between the predictor variables, nicotine withdrawal and depressed mood were tested using two separate logistic regressions to avoid issues related to multicollinearity. Postcessation self-efficacy was negatively associated with Week 1 nicotine withdrawal $(r(229)=-.36, p<.001)$ and depressed mood $(r(226)=-$ $.32, p<.001)$. 
Table 1

Bivariate Correlation Matrix for Predictor Variables and Covariates

Variable

1

2

3

4

5

6

1. NW BL

2. $B D I B L$

$.55^{* *}$

3. ND BL

.02

.01

4. NW WK 1

$.28 * *$

$.19 * *$

.11

5. BDI WK 1

$.33^{* *}$

$.41 * *$

.04

$.53^{* *}$

6. PSE

$-.06$

$-.16 * \quad-.040$

$-.36^{* *}$

$-.32 * *$

Note: $\mathrm{NW}$ BL = nicotine withdrawal at baseline; $\mathrm{BDI} \mathrm{BL}=$ depressed mood at baseline; ND BL = nicotine dependence at baseline; NW WK 1 = nicotine withdrawal at Week 1; BDI WK 1 = depressed mood at Week 1 ; PSE = postcessation self-efficacy at Week 1 ${ }^{*} p<.05 ;{ }^{*} p<.01$

Descriptive Statistics

Table 2 provides data on demographic and smoking history at baseline.

Approximately two-thirds of the sample $(N=266)$ are male $(63.5 \%)$ with a mean age of $48(S D=11.11)$. Participants smoked on average 24 cigarettes per day $(S D=8.68)$ and the sample had a mean nicotine dependence score of 6 , which indicates a high dependency. Of those who made a quit attempt in the previous year ( $>24$ hours) the average number of attempts was $2.12(S D=7.57)$. Participants classified themselves as either married (44.0\%), never married (19.2\%), divorced (15.0\%), living common law (12.4\%), separated $(6.8 \%)$ or widowed $(2.3 \%)$. At the time of the baseline assessment, 
the majority of the sample was employed full-time (70.3\%), followed by retired $(9.8 \%)$, part-time (9.4\%), disability leave (5.3\%) and unemployed (4.1\%).

Table 2

Baseline Characteristics of the Sample

\begin{tabular}{|c|c|c|c|}
\hline Variable & $n$ & $M(S D)$ & $\%$ \\
\hline Age & 266 & $47.97(11.11)$ & - \\
\hline Years of education & 265 & $14.17(2.72)$ & - \\
\hline Age of first cigarette & 265 & $14.91(4.37)$ & - \\
\hline Number of years smoked & 264 & $29.44(11.98)$ & - \\
\hline Number of cigarettes smoked/day & 264 & $24.00(8.68)$ & - \\
\hline $\begin{array}{l}\text { Number of quit attempts in the } \\
\text { past year }\end{array}$ & 257 & $2.12(7.57)$ & - \\
\hline NW BL & 252 & $0.97(0.71)$ & - \\
\hline BDI BL & 266 & $0.29(0.24)$ & - \\
\hline ND BL & 258 & $6.00(2.10)$ & - \\
\hline Gender (Male) & 266 & - & 63.5 \\
\hline Group (Experimental) & 266 & - & 49.2 \\
\hline Exposed to smoking in the home (yes) & 266 & - & 32.7 \\
\hline Exposed to smoking in the workplace (yes) & 262 & - & 29.4 \\
\hline $\begin{array}{l}\text { Previous use of smoking cessation } \\
\text { medications (yes) }\end{array}$ & 264 & - & 72.7 \\
\hline
\end{tabular}

Note. $N=266$. Sample sized vary due to missing data on these variables NW BL = nicotine withdrawal at baseline; $B D I B L=$ depressed mood at baseline; $N D B L=$ nicotine dependence at baseline $M=$ mean; $S D=$ standard deviation 


\section{Test of Main Effects}

Three logistic regression analyses were conducted to test main effects of Week 1 nicotine withdrawal, depressed mood, and postcessation self-efficacy on continuous abstinence from smoking at Week 3. At Week 3 follow-up, 131 (49\%) participants had successfully remained abstinent while 135 (51\%) had relapsed to smoking.

Hypothesis I. Lower nicotine withdrawal severity score at Week 1 post-TQD will predict continuous abstinence at Week 3 post-TQD, after controlling for preabstinence nicotine withdrawal score. A logistic regression analysis was performed to assess the impact of Week 1 nicotine withdrawal on Week 3 smoking status while controlling for baseline nicotine dependence, baseline nicotine withdrawal score and treatment group. The pooled results of the logistic regression are in Table 3.

Table 3

Summary of Logistic Regression Analysis for Nicotine Withdrawal and Continuous Abstinence at Week $3(N=266)$

\begin{tabular}{lllll}
\hline Variable & $B$ & $S E B$ & $p$ & $O R(95 \% C l)$ \\
NW BL & .22 & .25 & .366 & $1.25(0.77,2.04)$ \\
ND BL & -.23 & .07 & .002 & $0.80^{*}(0.69,0.92)$ \\
Group & -.32 & .28 & .245 & $0.73(0.42,1.25)$ \\
NW WK1 & -.59 & .22 & .007 & $0.56^{*}(0.36,0.85)$
\end{tabular}

Note: NW BL = nicotine withdrawal at baseline; ND BL = nicotine dependence at baseline; Group = randomization group; NW WK 1 = nicotine withdrawal at Week 1 $B=$ unstandardized coefficient; $S E B=$ standard error; $O R=$ odds ratio; $C l=$ confidence interval $* p<.01$ 
The odds of being smoke free at Week 3 are .56 less with a one unit increase in nicotine withdrawal, or the odds of being smoke-free at Week 3 are decreased by $44 \%$ with one unit increase in Week 1 nicotine withdrawal. Those smoking at Week 3 had a pooled Week 1 mean nicotine withdrawal score of $1.54(S E=0.07)$ whereas those who were smoke-free at Week 3 had pooled Week 1 mean nicotine withdrawal score of 1.22 $(S E=0.07)$. Thus those who had higher nicotine withdrawal scores at Week 1 had a significantly higher probability of relapse by Week 3 .

\section{Hypothesis II. Lower depressed mood score at Week 1 post-TQD will predict}

continuous abstinence at Week 3 post-TQD, after controlling for preabstinence depressed mood score.

A logistic regression analysis was performed to assess the impact of Week 1 depressed mood on Week 3 continuous abstinence, while controlling for baseline nicotine dependence, baseline depressed mood score and treatment group. The pooled results of the logistic regression are in Table 4. The analysis did not show an effect of Week 1 depressed mood on continuous abstinence at Week 3; those who were smokefree at Week 3 did not have significantly lower depressed mood scores $(M=0.22, S E=$ 0.02 ) compared to those who were smoking $(M=0.28, S E=0.02)$. 
Table 4

Summary of Logistic Regression Analysis for Depressed Mood and Continuous Abstinence at Week $3(N=266)$

\begin{tabular}{lllll}
\hline Variable & $B$ & $S E B$ & $p$ & $O R(95 \% C l)$ \\
BDI BL & -.71 & .69 & .310 & $0.49(0.13,1.93)$ \\
ND BL & -.24 & .07 & .001 & $0.79 *(0.69,0.91)$ \\
Group & -.40 & .27 & .14 & $0.67(0.39,1.14)$ \\
BDI WK1 & -.98 & .83 & .24 & $0.38(0.07,1.94)$
\end{tabular}

Note: $\mathrm{BDI} \mathrm{BL}=$ depressed mood at baseline; ND BL = nicotine dependence at baseline; Group = randomization group; BDI WK 1 = depressed mood at Week 1

$B=$ unstandardized coefficient; $S E B=$ standard error; $O R=$ odds ratio; $\mathrm{Cl}=$ confidence interval

${ }^{*} p<.01$

Hypothesis III. Higher postcessation self-efficacy score at week one post-TQD will

predict continuous abstinence at week three. A logistic regression analysis was

performed to assess the impact of Week 1 postcessation self-efficacy on Week 3

continuous abstinence while controlling for baseline nicotine dependence and

treatment group. The pooled results of the logistic regression are in Table 5. 
Table 5

Summary of Logistic Regression Analysis for Postcessation Self-Efficacy and Continuous Abstinence at Week $3(N=266)$

\begin{tabular}{lllll}
\hline Variable & $B$ & $S E B$ & $p$ & $O R(95 \% C l)$ \\
ND BL & -.24 & .07 & .001 & $0.79 * *(0.69,0.91)$ \\
Group & -.41 & .27 & .13 & $0.66(0.39,1.13)$ \\
PSE & .40 & .16 & .012 & $1.50 *(1.09,2.05)$
\end{tabular}

Note: ND BL = nicotine dependence at baseline; Group = randomization group; PSE = postcessation self-efficacy at Week 1

$B=$ unstandardized coefficient; $S E B=$ standard error; $O R=$ odds ratio; $C l=$ confidence interval

${ }^{*} p<.05 ;{ }^{* *} p<.01$

A significant relationship was found between postcessation self-efficacy and smoking status wherein the odds of being smoke free at Week 3 increased by $50 \%$ with one unit increase in postcessation self-efficacy at Week 1 . Those who were smoke free at Week 3 had a higher pooled mean self-efficacy score at Week $1(M=3.70, S E=0.8)$ compared to those who were smoking $(M=3.32, S E=0.10)$.

Test of Mediation Hypothesis

Hypothesis IV. The hypothesized causal relationship in hypotheses I and II will be mediated by postcessation self-efficacy scores at week one. As no significant relationship was identified for hypothesis II, mediation analysis was only carried out for hypothesis I. To test the mediation hypothesis the INDIRECT procedure for SPSS was used (Preacher \& Hayes, 2011) to derive the total, direct and indirect effect of nicotine withdrawal at Week 1 on continuous abstinence at Week 3 through postcessation selfefficacy: 
(1)

(2)

The covariates included with the predictor variables were nicotine dependence at baseline, nicotine withdrawal score at baseline and randomization group. Logistic regression was used to test Equations 1 and 3 and ordinary least-squares (OLS) regression was used to test coefficients in Equation 2.

The INDIRECT (Preacher \& Hayes, 2011) procedure was run for each of the $N=$ 15 imputed datasets separately and the coefficients and standard errors were pooled (Rubin, 1987; Sobel, 1982). Figure 1 summarizes the pooled results of pathways $a, b, c$ and $c$. 


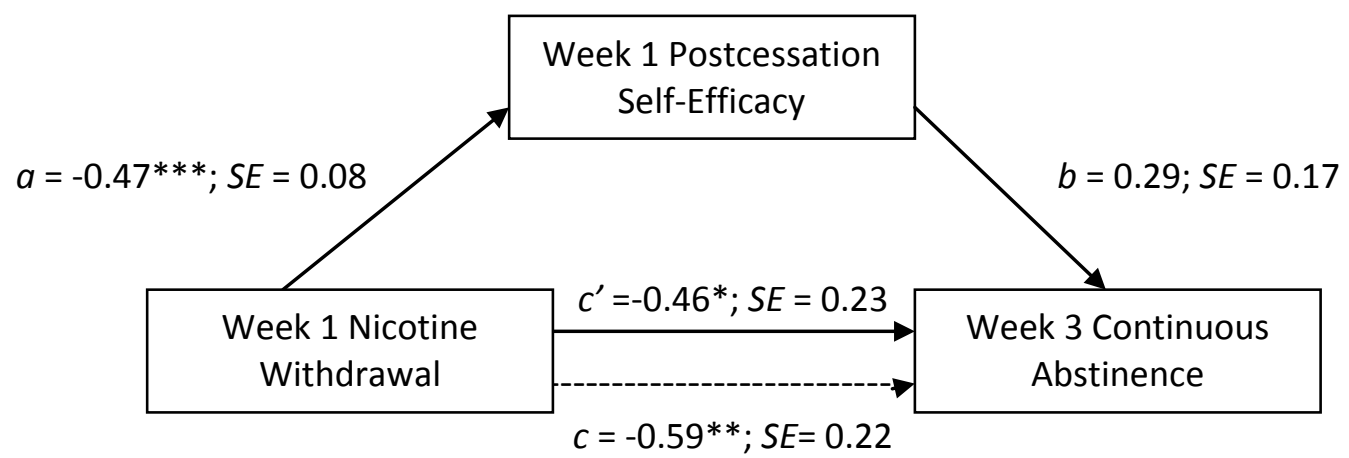

Figure 1. Path coefficients for indirect mediation analysis on Week 3 continuous abstinence.

Note. Dotted line (c pathway) denotes the total effect of Week 1 nicotine withdrawal on Week 3 continuous abstinence when postcessation self-efficacy is not included as a mediator, $c^{\prime}$ pathway indicates the effect of Week 1 nicotine withdrawal on Week 3 continuous abstinence controlling for postcessation self-efficacy. Pathways $b, c$ and $c$ ' are pooled unstandardized logistic regression coefficients, pathway $a$ is a pooled unstandardized OLS regression coefficient.

$* p<.05, * * p<.01, * * * p<.001$

The coefficient for the indirect effect of Week 1 nicotine withdrawal on Week 3 continuous abstinence through postcessation self-efficacy was, $a b=-0.14, S E=0.08$. To test the significance of the indirect effect ( $a b$ pathway), the Sobel test was calculated with the pooled coefficients and standard errors (Preacher \& Leonardelli, 2001; Sobel, 1982). The results revealed that there was no significant mediation effect of postcessation self-efficacy on Week 1 nicotine withdrawal and Week 3 continuous abstinence $(z=-1.64, S E=.08, p=.10)$.

\section{Discussion}

The current study examined the mediating effect of postcessation self-efficacy on nicotine withdrawal and short-term abstinence in a sample of smokers ready to quit who were receiving practical counselling and NRT. The prospective nature of the study design, inclusion of community smokers and the assessment of a novel mediator of 
nicotine withdrawal provides an opportunity to enhance our understanding of predictors of smoking cessation outcomes with the purpose of improving the treatment of nicotine dependence. Overall, nicotine withdrawal and self-efficacy at Week 1 postTQD predicted continuous abstinence at Week 3 while depressed mood did not. In all three analyses of main effects, baseline nicotine dependence significantly predicted abstinence, i.e. those who were more highly dependent on nicotine were less likely to be smoke-free at Week 3. The results of the study did not support a mediating role of postcessation self-efficacy on nicotine withdrawal and abstinence.

\section{Main Effects Analyses}

Those individuals who experienced increased nicotine withdrawal severity at Week 1 were less likely to be smoke-free at Week 3 . This finding is consistent with past research assessing nicotine withdrawal symptoms and short-term cessation outcomes (al'Absi, 2004; Covey et al., 1990; Gritz et al., 1991; Norregaard et al., 1993; Robinson et al., 1992; West et al., 1989). Overall participants in the study reported, on average, slight to mild nicotine withdrawal at Week 1 post-TQD. This finding is also consistent with past studies that have used the average MWS score as a measure of nicotine withdrawal (Etter \& Hughes, 2006; Etter et al., 2013).

Participants who had relapsed to smoking had a higher mean depressed mood score at Week $1(M=0.28, S E=0.02)$ compared to those who had remained smoke-free $(M=0.22, S E=0.02)$, however this depressed mood score did not predict smoking cessation outcomes at Week 3 . This is contrast to the results of previous research that have established depressed mood as an individual withdrawal symptom consistently 
predictive of smoking cessation outcomes (Baker et al., 2004; Etter et al., 2013; Hughes, 2007a). A methodological issue that may have resulted in the divergent findings of the current study was the use of the BDI-II as the measure of depressed mood.

The emergence of depressive symptoms measured by the BDI-II may not reflect clinically meaningful depression that would predict smoking outcomes. This study found that depressed mood scores were lower postcessation; mean precessation depressed mood score was $M=0.29(S E=0.02)$ while Week 1 mean depressed mood score was $M$ $=0.25(S E=0.02)$ indicating that depressed mood decreased post-TQD. The retest effect "defined as the systematic effect of repeated test taking on the scores of subsequent administrations" (Longwell \& Truax, 2005 p.266) may account for the lower BDI-II scores postcessation. Research suggests re-administration of the BDI-II leads to decreases in scores over time (Ahava, lannone, Grebstein \& Schirling, 1998; Longwell \& Truax, 2005).

Ahava et al. (1998) assessed the test-retest reliability of the BDI in a non-clinical sample of college students ( $N=197 ; 59.1 \%$ female) who were not receiving an intervention. Students were administered the BDI weekly for eight weeks, at the same day and time each week. The results indicated a significant decrease in BDI score over time. Post hoc tests revealed that BDI scores declined significantly upon weekly administration from Weeks 1 to 5 , but not from Week 5-8.

Longwell and Truax (2005) tested the decrease in BDI-II scores at differential testing intervals (weekly, monthly, and bimonthly) in a sample of non-clinical participants ( $n=237 ; 70 \%$ female) who were not receiving an intervention. Participants 
were randomized to complete the BDI-Il at weekly, monthly, or bimonthly intervals. BDIIl scores were found to significantly decrease for the weekly administration group only, indicating that the more frequently the measure is administered, the more significant the decline in scores over time.

Thus, the decline in mean depressed mood scores postcessation is likely due to the retest effect. As the BDI-II is sensitive to a decline in depressed mood scores when administered frequently, such as in the present study, it may be problematic to use the BDI-II to assess emergence of depressed mood postcessation, since a decline in score may be related to measurement, not actual symptomatology.

The predictive variables nicotine withdrawal and depressed mood were moderately associated at both baseline and Week 1. Many of the items on the MWS and the BDI-II assess similar variables including sadness, agitation, irritability, changes in appetite, difficulty concentrating, tiredness and fatigue (Beck et al., 1996; Hughes, 2007b). The correlation between measures of nicotine withdrawal and depressed mood is likely associated with the similarity to questionnaire items but, despite this, nicotine withdrawal predicted abstinence while depressed mood did not. As described above, this may be due to methodological issues regarding suitability of the BDI-II to assess emergence of depressed mood postcessation. Future research is needed to determine the most accurate measurement for assessing abstinence-induced depressed mood in smokers with and without a history of depression.

Participants who had higher postcessation self efficacy measured at Week 1 were significantly more likely to be abstinent from smoking at Week 3 . Belief that one 
could refrain from smoking when faced with various internal (nervous, anxious, angry) and external (after a meal, while having coffee or tea, socializing with smokers) cues increased the likelihood of remaining abstinent during the first three weeks after a quit attempt. This is consistent with past research that has shown increased postcessation self-efficacy predicts abstinence from smoking (Gwaltney et al., 2009). Postcessation self-efficacy was negatively correlated with Week 1 nicotine withdrawal and Week 1 depressed mood), suggesting there is an association between increases in nicotine withdrawal symptom severity and decreases in confidence to remain smoke-free. Mediation Analyses

The findings of the mediation analysis indicate nicotine withdrawal does not lead to relapse through diminished postcessation-self-efficacy. It should be noted here, that all participants were randomized to an active NRT treatment group. Both standard dose NRT and titrated NRT have been found to increase rates of abstinence (Stead, Perera, Bullen, Mant \& Lanacaster, 2008), by addressing the physiological symptoms of nicotine withdrawal (Piasecki et al., 2003b; Stead et al., 2009). Despite the fact that randomization group was controlled for in the analysis, it is possible that receiving treatment for nicotine withdrawal symptoms reduced the overall symptom severity leading to a diminished effect on postcessation self-efficacy.

Contrary to the findings of Morrell et al. (2011), this study did find a significant relationship between Week 1 nicotine withdrawal and postcessation self-efficacy (pathway a). Those who experience increased nicotine withdrawal severity concurrently experienced lower postcessation self-efficacy. However, as nicotine withdrawal was not 
measured prospectively, it cannot be determined if the negative physiological symptoms of nicotine withdrawal led to a decrease in self-efficacy or if there is another factor that accounts for the association between these two variables.

There is research that suggests postcessation self-efficacy is a reflection, not a predictor, of smoking behavior (Perkins, Parzynski, Mercincavage Conklin \& Fonte, 2012). This is contrary to self-efficacy theory which posits that self-efficacy causes behavior change (Bandura, 1977). Perkins et al. (2012) hypothesized that if postcessation self-efficacy predicts behaviours then it causes change, whereas if behaviour predicts postcessation self-efficacy then it is a reflection of behaviour change. To test this hypothesis, the authors performed secondary data analysis of the results of two clinical trials investigating the efficacy of smoking cessation medications, NRT versus placebo $(N=209)$ and varenicline (a prescription medication used to treat nicotine dependence) versus placebo $(N=123)$. Participants in both studies were seen daily on the first week of their quit attempt. Abstinence was assessed with a self-report of not smoking in the last 24 hours and a bio-chemical CO confirmation of $<5 \mathrm{ppm}$. The results indicated a bidirectional association between smoking behavior and postcessation self-efficacy whereby daily self-efficacy predicted next day's abstinence (when controlling for current day's smoking status) and current day's abstinence predicted next day's postcessation self-efficacy score (controlling for current day's selfefficacy score). The authors concluded that, during the initial week of a quit attempt, the findings did support self-efficacy as a causal determinant of smoking behavior, 
however they also indicate that postcessation self-efficacy may be a reflection of current behaviour.

It may be possible that increases in nicotine withdrawal are related to selfefficacy scores in that postcessation self-efficacy is reflecting current smoking behavior, which, as this study has shown, is related to nicotine withdrawal severity. This may also explain why the direct effect of postcessation self-efficacy on abstinence controlling for Week 1 nicotine withdrawal was not significant, contrary to what was found in the main effects analysis. Future research is needed to better understand the relationship between nicotine withdrawal and postcessation self-efficacy specifically whether nicotine withdrawal can prospectively predict self-efficacy scores and the subsequent effect this may have on abstinence from smoking.

\section{Limitations of the Current Study}

There are study limitations that should be noted. The eligibility criteria for the clinical trial excluded any individual who self-reported that they were currently suffering from depression or had been diagnosed with depression or treated with an antidepressant in the previous 12 months; had a past or present history of psychosis, panic disorder, bipolar disorder; had demonstrated drug or alcohol abuse or dependence within the last year; or scored moderate or more $(\geq 20)$ on the baseline depression inventory. A recent US population-based study published on smoking and mental illness ( $N=43,093$; Smith, Mazure \& McKee, in press) found that $39 \%$ of current smokers reported a diagnosis of mental illness in the last year. Those with a current diagnosis of mental illness were 3.23 times more likely to be a current smoker, 
compared to those who had no previous diagnosis. Thus, the current study excluded a significant proportion of the 'smoking' population potentially limiting the generalizability of the results.

A second limitation of the study, as mentioned above, is that all participants were being treated with NRT for nicotine withdrawal symptoms. Perhaps increased nicotine withdrawal, such as might be observed in untreated smokers making a quit attempt, would have had a greater impact on postcessation self-efficacy. Future studies should investigate mediation effect of postcessation self-efficacy on nicotine withdrawal and abstinence in a sample of untreated smokers making a quit attempt.

A methodological limitation to the current study was the use of pooled standard errors derived from the delta method, or the Sobel test (Sobel, 1982), for the analysis of the mediation effect. One of the assumptions of Sobel's method is that the sampling distributions of the total and indirect effects are normal (Preacher \& Hayes, 2008). The indirect effect, however, is rarely normal. To address this issue of non-normality, researchers are increasingly using bootstrap confidence intervals to test for the indirect effects of mediating variables (Preacher \& Hayes, 2008). Unfortunately, bootstrapping procedures are not yet available with the SPSS INDIRECT (Preacher \& Hayes, 2011) macro using a multiple imputation dataset, thus, the Sobel method was used in lieu of a bootstrap method to test for mediation.

\section{Conclusions}

A recent report on tobacco use trends in Canada (Health Canada, 2013) stated that $43 \%$ of smokers do not seek out any form of assistance (medication, help-line, 
social support, cessation programs) when they make a quit attempt. Smokers who quit without any assistance (self-quitters) and those who seek out assistance with quitting smoking (group-quitters), have been found to significantly differ in relapse rates at one month, $71.2 \%$ versus $43.6 \%$ for self-quitters and group-quitters respectively (Elfeddali et al., 2011).

All participants in the trial had sought assistance with quitting; they were recruited primarily from radio and print advertisements and inclusion criteria included willingness to use smoking cessation medications and receive behavioural counseling. In addition, at baseline, $72.7 \%$ of participants reported that they had used a smoking cessation medication during a previous quit attempt. In contrast, Health Canada (2013) reports that, among current and former smokers who had quit in the past two years, only $35 \%$ used a smoking cessation medication. The results of the current sample are generalizable to treatment seeking smokers, but may not be applicable to self-quitters. However, as the goal of the current study is to better understand the factors that lead to abstinence from smoking with the aim of improving smoking cessation interventions, those who seek assistance with quitting are an appropriate sample for this study.

Despite the fact that all study participants were receiving NRT and behavioural counseling, relapse rates were $35 \%$ and $51 \%$ at Week 1 and Week 3 respectively. These relapse rates indicate that there are still significant improvements to be made in smoking cessation interventions, especially during the initial weeks of a quit attempt when the probability of relapse is the highest (Piasecki, 2006). 
Ultimately, the results of the current study indicate that postcessation selfefficacy does not mediate the effect of nicotine withdrawal on abstinence, but clearly there is a relationship between these two factors. Regardless of whether increases in nicotine withdrawal lead to decreases in postcessation self-efficacy or postcessation self-efficacy scores reflect current smoking behavior, treating the symptoms of nicotine withdrawal will increase the likelihood of maintaining abstinence which may, in turn, increase postcessation self-efficacy. The results of this study would support the treatment of the symptoms of nicotine withdrawal using appropriate smoking cessation medications (Fiore et al., 2008) while concurrently intervening to fortify postcessation self-efficacy.

Future research should continue to explore the dynamic relationship between nicotine withdrawal and postcessation self-efficacy in untreated smokers and might also seek to explore optimal measures for assessing abstinence-induced depressed mood. A clear relationship between the presence of psychiatric co-morbidities and the prevalence of smoking also will require a more considered understanding of how smoking cessation interventions might be designed and delivered so as to specifically address associated mental health issues e.g. depression. 


\section{References}

Ahava G.W., Iannone, .C, Grebstein, L., \& Schirling, J. (1998). Is the Beck Depression Inventory reliable over time? An evaluation of multiple test-retest reliability in a nonclinical college student sample. Journal of Personality Assessment, 70(2), 222231.

Ajzen, I. (1991). The theory of planned behavior. Organizational Behavior and Human Decision Processes, 50, 179-211.

al'Absi, M., Hatsukami, D., Davis, G. L., \& Wittmers, L. E. (2004). Prospective examination of effects of smoking abstinence on cortisol and withdrawal symptoms as predictors of early smoking relapse. Drug and Alcohol Dependence, 73, 267-278. American Psychiatric Association. (2013). Diagnostic and Statistical Manual of Mental Disorders (Fifth ed.). Arlington, VA: American Psychiatric Publishing. American Psychiatric Association (2000). Diagnostic and Statistical Manual of Mental Disorders (Fourth ed., text revision). Washington, DC: American Psychiatric Association.

Anthony, J. C., Warner, L. A., \& Kessler, R. C. (1994). Comparative epidemiology of dependence on tobacco, alcohol, controlled substances, and inhalants: Basic findings from the National Comorbidity Survey. Experimental and Clinical Psychopharmacology, 2, 244-268.

Aubin, H. J. (2009). Management of emergent psychiatric symptoms during smoking cessation. Current Medical Research and Opinions, 25 (2), 519-525. 
Baker, T. B., Piper, M. E., McCarthy, D. E, Majeskie, R. M., \& Fiore, M. C. (2004). Addiction motivation reformulated: An affective processing model of negative reinforcement. Psychology Review, 111 (1), 33-51.

Bandura, A. (1977). Self-efficacy: Toward a unifying theory of behavioral change. Psychological Review, 84, 191-215.

Bandura, A. (1986). Social foundations of thought and action; A social cognitive theory. Englewood Cliffs, NJ: Prentice-Hall.

Bandura, A. (1997). Self-efficacy: The exercise of control. New York: W.H. Freeman.

Beck, A., Steer, R., \& Brown, G. (1996). The Beck Depression Inventory-second edition manual. San Antonio, Tx: The Psychological Corporation.

Benowitz, N. L. (2008). Clinical pharmacology of nicotine: implications for understanding, preventing, and treating tobacco addiction. Clinical Pharmacological Theraupeutics, 83 (4), 531-541.

Benowitz, N. L. (2009) Pharmacology of nicotine: addiction, smoking-induced disease, and therapeutics. Annual Review Pharmacological Toxicology, 49, 57-71.

Benowitz, N.L. (2010). Nicotine Addiction. New England Journal of Medicine, 362 (24), 2295-2303.

Benowitz, N. L., Jacob, P. III., Ahijevych, K., Jarvis, M. J., Hall, S., LeHouezec, J., et al. (2002). Biochemical verification of tobacco use and cessation. Nicotine \& Tobacco Research, 4, 149-159.

Berndt, N., C., Hayes, A., F., Verboon, P., Lechner, L., Bolman, C. \& De Vries, (2013). Self-efficacy mediates the impact of craving on smoking abstinence in low to 
moderately anxious patients: Results of a moderated mediation approach. Psychology of Addictive Behaviors, 27(1), 113-124.

Brandon, T. H., Herzog, T. A, Irvin, J. E., \& Gwaltney, C. J. (2004). Cognitive and social learning models of drug dependence: implications for the assessment of tobacco dependence in adolescents. Addiction, 99 (s1), 51-77.

Breslau, N., Kilbey, M. M., \& Andreski, P. (1992). Nicotine withdrawal symptoms and psychiatric disorders: Findings from an epidemiologic study of young adults. American Journal of Psychiatry, 149, 464-469.

Cinciripini, P. M., Wetter, D. W., Fouladi, R. T., Blalock, J. A., Carter, B. L., \& Cinciripini, L. G, et al. (2003). The effects of depressed mood on smoking cessation: mediation by postcessation self-efficacy. Journal of Consulting and Clinical Psychology, 71 (2), 292301.

Covey L. S., Glassman A. H., \& Stetner F. (1990). Depression and depressive symptoms in smoking cessation. Comprehensive Psychiatry, 31, 350-354.

Cummings K. M., Jaen, C., \& Guivino, G. (1985). Circumstances surrounding relapse in a group of recent ex smokers. Preventative Medicine, 14, 195-202.

De Biasi, M. \& Dani, J. A. (2011). Reward, Addiction, Withdrawal to Nicotine. Annual Review Neuroscience, 34, 105-130.

Dornelas, E. A., Sampson, R. A., Gray, J. F., Waters, D., \& Thompson, P. D. (2000). A randomized controlled trial of smoking cessation counseling after myocardial infarction. Preventive Medicine, 30, 261-268. 
Eissenberg, T. (2004). Measuring the emergence of tobacco dependence: the contribution of negative reinforcement models. Addiction, 99(s1), 5-29.

Elfeddali, I., Bolman, C., Candel, M. J. J. M., Wiers, R. W., \& De Vries, H. (2012). The role of self-efficacy, recovery self-efficacy, and preparatory planning in predicting shortterm smoking relapse. British Journal of Health Psychology, 17 (1), 185-201.

Etter, J. F. (2005). A self-administered questionnaire to measure cigarette withdrawal symptoms, the Cigarette Withdrawal Scale. Nicotine \& Tobacco Research, 7, 47-57.

Etter, J. F., Bergman, M. M., Humair, J. P., \& Perneger, T. V. (2000). Development and validation of a scale measuring self-efficacy of current and former smokers. Addiction, 95, 901-913.

Etter, J. F., \& Hughes J. R. (2006). A comparison of the psychometric properties of three cigarette withdrawal scales. Addiction, 101, 362-372.

Etter J. F., Ussher, M., \& Hughes, J. R. (2013). A test of proposed new tobacco withdrawal symptoms. Addiction, 108, 50-59.

Fiore, M., Jaen, C., Baker, T., Bailey, W.C., Benowitz, N.L., Curry, S.J. (2008). Treating Tobacco Use and Dependence: 2008 Update. Clinical Practice Guidelines. Rockville, MD: Public Health Service.

Glauthier, S. (2004). Measures and models of nicotine dependence: positive reinforcement. Addiction, 99(s1), 30-50.

Gritz, E. R., Carr C. R., \& Marcus, A. C.(1991).The tobacco withdrawal syndrome in unaided quitters. British Journal of Addiction, 86, 57-69. 
Gwaltney, C. J., Metrik, J., Kahler, C. W., \& Shiffman, S. (2009). Self-efficacy and smoking cessation: A meta-analysis. Psychology of Addictive Behaviors, 23, 56-66.

Gwaltney, C. J., Shiffman, S., Balabanis, M. H., \& Paty, J. A. (2005). Dynamic self-efficacy and outcome expectancies: Prediction of smoking and relapse. Journal of Abnormal Psychology, 114, 661-675.

Hall, S. M., Ginsberg, D., \& Jones R. T. (1986) Smoking cessation and weight gain. Journal of Consulting and Clinical Psychology, 54, 342-346.

Hatsukami, D. K., Grillo, M., Boyle, R., Allen, S., Jensen, J., Bliss, R., et al. (2000).

Treatment of spit tobacco users with transdermal nicotine system and mint snuff. Journal of Consulting and Clinical Psychology, 68, 241-249.

Haug, S., Meyer, C., Ulbricht, S., Schorr, G., Rüge, J., Rumpf H. J. et al. (2010). Predictors and moderators of outcome in different brief interventions for smoking cessation in general medical practice. Patient Education \& Counseling, 78, 57-64.

Hayes, A. F. (2011). Indirect (version 4.2). [Computer software]. Columbus, OH: The Ohio State University.

Health Canada. (2013). Canadian Tobacco Monitoring Survey 2012. Ottawa, Ontario: The Government of Canada.

Heatherton, T. F., Kozlowski, L.T., Frecker, R.C., \& Fagerstrom, K. O. (1991). The Fagerstrom Test for Nicotine Dependence: a revision of the Fagerstrom Tolerance Questionnaire. British Journal of Addiction, 9, 1119-1127. 
Hendricks, P. S., Delucchi, K. L., \& Hall, S. M. (2010) Mechanisms of change in extended cognitive behavioral treatment for tobacco dependence. Drug \& Alcohol Dependence, 109, 114-119.

Henningfield, J. E. (1995). Symptoms of substance dependence associated with use of cigarettes, alcohol, and illicit drugs-United States, 1991-1992. Morbidity and Mortality Weekly Report, 44, 830-839.

Hitsman, B., Borrelli, B., McChargue, D. E., Spring, B., \& Niaura, R. (2003). History of depression and smoking cessation outcome: A meta-analysis. Journal of Consulting and Clinical Psychology, 71 (4), 657-663.

Hosmer, D. W. \& Lemeshow, S. (2000). Applied Logistic Regression, Second Ed. New York: Wiley.

Hughes, J. R. (1992). Tobacco withdrawal in self-quitters. Journal of Consulting and Clinical Psychology, 60, 689-697.

Hughes, J. R. (2007a). Effects of abstinence from tobacco: Etiology, animal models, epidemiology, and significance: A subjective review. Nicotine \& Tobacco Research, 9(3), 329-339.

Hughes, J. R. (2007b). Effects of abstinence from tobacco: Valid Symptoms and time course. (2007) Nicotine \& Tobacco Research, 9(3), 315-327.

Hughes, J. R. (2007c). Measurement of the effects of abstinence from tobacco: a qualitative review. Psychology of Addictive Behaviours, 21 (2), 127-137. 
Hughes, J. R., Gust, S. W., Skoog, K., Keenan, R., \& Fenwick, J. W. (1991). Symptoms of tobacco withdrawal: A replication and extension. Archives of General Psychiatry, 48, 52-59.

Hughes, J. R., \& Hatsukami, D. K. (1986). Signs and symptoms of tobacco withdrawal. Archives of General Psychiatry, 43, 289-294.

Hughes, J. R., Keely, J. P., Niaura, R. S, Ossip-Klein, D. J., Richmond, R. L., \& Swan, G. E. (2003). Measures of abstinence in clinical trials: issues and recommendations. Nicotine \& Tobacco Research, 5, 13-25.

Kenford, S. L., Fiore, M. C., Jorenby, D. E., Smith, S. S., Wetter, D., \& Baker, T. B.(1994). Predicting smoking cessation: Who will quit with and without the nicotine patch. Journal of the American Medical Association, 271, 589-594.

Killen, J. D., Fortmann, S. P., Schatzberg, A., Hayward, C., \& Varady, A. (2003). Onset of major depression during treatment for nicotine dependence. Addictive Behaviors, $28,461-470$.

Koob, G. F., \& Le Moal, M. (1997) Drug abuse: hedonic homeostatic dysregulation. Science, $278,52-58$.

Maddux, J. E., \& Rogers, R. W. (1983). Protection motivation theory and self-efficacy: A revised theory of fear appeals and attitude change. Journal of Experimental Social Psychology, 19, 469-479.

Longwell, B.T., \& Truax, P. (2005). The differential effects of weekly, monthly, and bimonthly administrations of the Beck Depression Inventory -II: psychometric properties and clinical implication. Behavior Therapy, 36, 265-275. 
Meland, E., Maeland, J. G., \& Laerum, E. (1999). The importance of self-efficacy in cardiovascular risk factor change. Scandinavian Journal of Public Health, 27, 11-17.

Mokdad, A. H., Marks, J. S., Stroup, D. F., \& Gerberding, J. L. (2004). Actual causes of death in the United States, 2000. Journal of American Medical Association, $291,1238-1245$.

Morrell, H. E. R, Skarbek, E. A, \& Cohen, L.M. (2011). The relationship between selfefficacy and nicotine withdrawal severity among adult smokers. Addiction Research and Theory, 19(6), 494-503.

Norregaard, J., Tonnesen, P., \& Petersen L. (1993). Predictors and reasons for relapse in smoking cessation with nicotine and placebo patches. Preventive Medicine, 22, 261271.

Ockene, J. K., Emmons, K. M., Mermelstein, R.J., Perkins, K.A., Bonollo, D. S., Voorhees, C. C. et al. (2000) Relapse and maintenance issues for smoking cessation. Health Psychology, 19, 17-31.

O'Connell, K. A., \& Martin, E. J. (1987) Highly tempting situations associated with abstinence, temporary lapse, and relapse among participants in smoking cessation programs. Journal of Consulting and Clinical Psychology, 55, 367-371.

Paolini, M., \& De Biasi, M. (2011). Mechanistic insights into nicotine withdrawal. Biochemical Pharmacology, 82 (8), pg. 996-1007.

Patten, C. A., \& Martin, J. E. (1996). Does nicotine withdrawal affect smoking cessation? Clinical and theoretical issues. Annals of Behavioral Medicine, 18, 190-200. 
Percisco, A.M. (1992) Predictors of smoking cessation in a sample of Italian smokers. International Journal of the Addictions, 27, 683-695.

Perkins, K. A., Grobe, J. E., D’Amico, D., Fonte, C., Wilson, A. S., \& Stiller, R. L. (1996). Low-dose nicotine nasal spray use and effects during initial smoking cessation. Experimental and Clinical Psychopharmacology, 4, 157-165.

Perkins, K.A., Karelitz, J.L, \& Jao, N.C. (2013). Optimal carbon monoxide criteria to confirm 24-hr smoking abstinence. Nicotine \& Tobacco Research, 15 (5), 978-982.

Perkins, K.A., Parzynski, C., Mercincavage, M., Conklin, C.A., \& Fonte, C.A. (2012). Is selfefficacy for smoking abstinence a cause of, or a reflection on, smoking behavior change? Experimental Clinical Psychopharmacology, 20(1), 56-62.

Piasecki, T. M. (2006). Relapse to smoking. Clinical Psychological Review, 26, 196 - 215.

Piasecki, T. M., Fiore, M. C., \& Baker, T.B. (1998). Profiles in discouragement: Two studies of variability in the time course of smoking withdrawal symptoms. Journal of Abnormal Psychology, 107, 238-251.

Piasecki, T. M., Jorenby, D. E., Smith, S. S., Fiore, M. C., \& Baker, T. B. (2003a). Smoking withdrawal dynamics: II. Improved tests of withdrawal-relapse relations. Journal of Abnormal Psychology, 112, 14-27.

Piasecki, T. M., Jorenby, D. E., Smith, S. S., Fiore, M.C., \& Baker, T.B. (2003b). Smoking withdrawal dynamics: III. Correlates of withdrawal heterogeneity. Experimental and Clinical Psychopharmacology, 11, 276-285. 
Piper, M. E., Schlam, T. R., Cook, J. W., Sheffer, M. A., Smith, S. S., Loh, W. Y., et al. (2011).Tobacco withdrawal components and their relations with cessation success. Psychopharmacology, 216(4), 569-578.

Pomerleau, C. S., Carton, S. M., Lutzke, M. L., Flessland, K. A., \& Pomerleau, O.F. (1994). Reliability of the Fagerstrom Tolerance Questionnaire and the Fagerstrom Test for Nicotine Dependence. Addictive Behaviour, 19, 33-39.

Pomerleau, C. S., Namenek-Brouwer, R.J, \& Pomerleau, O. F. (2001). Emergence of depression during early abstinence in depressed and non-depressed women smokers. Journal of Addictive Diseases, 20 (1), 73-80.

Preacher, K. J., \& Hayes, A. F. (2008). Asymptotic and resampling strategies for assessing and comparing indirect effects in multiple mediator models. Behavior Research Methods, 40, 879-891.

Preacher, K.J., \& Leonardelli, G. J. (2001). Calculation for the Sobel test: An interactive calculation tool for mediation tests. [Computer software]. http://quantpsy.org/sobel/sobel.htm

Prenger, R., Pieterse, M. E., Braakman-Jansen, L. M., Bolman, C., de Vries, H., \& Wiggers, L. C. (2013). A comparison of time-varying covariates in two smoking cessation interventions for cardiac patients. Health Education Research 28 (2), 300-3124.

Rehm, J., Ballunas D., Brochu S., Fischer B., Gnam W., Patra J., et al. (2006). The costs of substance abuse in Canada 2002. Ottawa, Ontario: Canadian Centre on Substance Abuse. 
Reid, J. L., Hammond, D., Burkhalter, R., \& Ahmed, R. (2012). Tobacco use in Canada: patterns and Trends, 2012 ed. Waterloo, Ontario: Propel Centre for Population Health Impact, University of Waterloo.

Robinson, M. D., Pettice, Y. L., Smith, W. A., Cederstrom, E. A., Sutherland, D. E., \& Davis, H. (1992). Buspirone effect on tobacco withdrawal symptoms: A randomized placebo-controlled trial. Journal of the American Board of Family Practice, 5, 1-9.

Rubin, D.B. (1987.) Multiple Imputation for Nonresponse in Surveys. New York: J. Wiley \& Sons.

Sarmet, J. M., Yoon, S.-Y. (Eds.). (2010). Gender, women and the tobacco epidemic. Geneva, Switzerland: World Health Organization.

Schafer, J., L., \& Graham, J.,W. (2002). Missing data: our view of the state of the art. Psychological Methods, 7 (2), 147-177.

Schnoll, R. A., Martinez, E., Tatum, K. L., Glass, M., Bernath, A., Ferris, D., Reynolds, P. (2011). Increased self-efficacy to quit and perceived control over withdrawal symptoms predict smoking cessation following nicotine dependence treatment. Addictive Behavior 36, (1-2), 144-147.

Shiffman, S., \& Jarvik, M. E. (1976). Smoking withdrawal symptoms in two weeks of abstinence. Psychopharmacology, 50, 35-39.

Shiffman, S., West, R. J., \& Gilbert, D. G. (2004). Recommendations for the assessment and of tobacco craving and withdrawal in smoking cessation trial. Nicotine \& Tobacco Research, 6 (4), 599-614. 
Smith, P.H., Mazure, C.M., \& McKee, S.A. (in press). Smoking and mental illness in the US population. Tobacco Control.

Sobel, M., E. (1982). Asymptotic confidence intervals forilndirect effects in structural equations models. In S. Leinhart (Ed.), Sociological Methodology (290-312). San Fransico: Jossey-Bass.

Stead, L. F., Perera, R., Bullen, C., Mant, D., \& Lanacaster, T. (2008). Nicotine replacement therapy for smoking cessation. Cochrane Database Systematic Review, 23(1), 1-160.

Strasser, A. A., Kaufmann, V., Jepson, C., Perkins, K. A., Pickworth, W. B., Wileyto, E. P., et. al (2005). Effects of different nicotine replacement therapies on postcessation psychological responses. Addictive Behaviors, 30, 9-17.

Swan, G. E., \& Denk, C. E. (1987) Dynamic models for the maintenance of smoking cessation: Event history analysis of late relapse. Journal of Behavioral Medicine, 10, 527-554.

Swan, G. E., Ward, M. M., \& Jack, L. M. (1996). Abstinence effects as predictors of 28day relapse in smokers. Addictive Behaviors, 21, 481-490.

Tabachnick, B. G., \& Fidell, L. S. (2007). Using multivariate statistics, Fifth Ed. Boston, MA: Pearson Education Inc.

Tobacco Strategy Advisory Group. (2010). Building on our gains, taking action now: Ontario's tobacco control strategy for 2011 - 2016. Toronto, Ontario: Minister of Health Promotion and Sport. 
Velicer, W. F., Diclemente, C. C., Rossi, J. S., \& Prochaska, J.O. (1990). Relapse situations and self-efficacy: An integrative model. Addictive Behaviors, 15, 271-283.

Wang, Y. P., \& Gorenstein, C. (2013). Assessment of depression in medical patients: A systematic review of the utility of the Beck Depression Inventory -II. Clinics, 68 (9), 1274-1287.

Welsch, S. K., Smith, S. S., Wetter, D. W., Jorenby, D. E., Fiore, M. C., \& Baker, T. B. (1999). Development and validation of the Wisconsin Smoking Withdrawal Scale. Experimental and Clinical Psychopharmacology, 7, 354-361.

West, R. J., Hajek, P., \& Belcher, M. (1989). Severity of withdrawal symptoms as a predictor of an attempt to quit smoking. Psychological Medicine, 19, 981-985.

West, R., Hajek, P., Stead, L., \& Stapleton, J. (2005). Outcome criteria in smoking cessation trials: proposal for a common standard. Addiction, 100, 299-303.

World Health Organization. (2008). WHO report on the global tobacco epidemic, 2008: The MPOWER package. Geneva, Switzerland: Author. 


\section{Appendix A}

\section{Minnesota Withdrawal Scale -Revised}

Instructions: Please rate yourself for the period of the last 24 hours.

Circle the appropriate response choice.

\begin{tabular}{|l|c|c|c|c|c|}
\cline { 2 - 5 } \multicolumn{1}{c|}{} & none & slight & mild & moderate & severe \\
\hline 1. Angry, irritable, frustrated & 0 & 1 & 2 & 3 & 4 \\
\hline 2. Anxious, nervous & 0 & 1 & 2 & 3 & 4 \\
\hline 3. Depressed mood, sad & 0 & 1 & 2 & 3 & 4 \\
\hline 4. Desire or craving to smoke & 0 & 1 & 2 & 3 & 4 \\
\hline 5. Difficulty concentrating & 0 & 1 & 2 & 3 & 4 \\
\hline 6. Increased appetite, hungry, weight gain & 0 & 1 & 2 & 3 & 4 \\
\hline 7. Insomnia, sleep problems, awakening at night & 0 & 1 & 2 & 3 & 4 \\
\hline 8. Restless & 0 & 1 & 2 & 3 & 4 \\
\hline 9. Impatient & 0 & 1 & 2 & 3 & 4 \\
\hline 10. Constipation & 0 & 1 & 2 & 3 & 4 \\
\hline 11. Dizziness & 0 & 1 & 2 & 3 & 4 \\
\hline 12. Coughing & 0 & 1 & 2 & 3 & 4 \\
\hline 13. Dreaming or nightmares & 0 & 1 & 2 & 3 & 4 \\
\hline 14. Nausea & 0 & 1 & 2 & 3 & 4 \\
\hline 15. Sore throat & 0 & 1 & 2 & 3 & 4 \\
\hline
\end{tabular}

Heart rate bpm $\mathrm{kg}$ 


\section{Appendix B}

Beck Depression Inventory-II (BDI-II)

Instructions: This questionnaire consists of 21 groups of statements. Please read each group of statements carefully, and then pick out the one statement in each group that best describes the way you have been feeling during the past two weeks, including today. Circle the number beside the statement you have picked. If several statements in the group seem to apply equally well, circle the highest number for that group. Be sure that you do not choose more than one statement for any group, including Item 16 (Changes in Sleeping Pattern) or Item 18 (Changes in Appetite).

\section{Sadness}

0 I do not feel sad.

1 I feel sad much of the time.

2 I am sad all of the time.

3 I am so sad or unhappy that I can't stand it.

\section{Pessimism}

0 I am not discouraged about my future.

1 I feel more discouraged about my future than I used to be.

2 I do not expect things to work out for me.

3 I feel my future is hopeless and will only get worse.

\section{Past Failure}

0 I do not feel like a failure.

1 I have failed more than I should have.

2 As I look back, I see a lot of failures.

3 I feel I am a total failure as a person.

\section{Loss of pleasure}

0 I get as much pleasure as I ever did from the things I enjoy.

1 I don't enjoy things as much as I used to.

2 I get very little pleasure from the things I used to enjoy.

3 I can't get any pleasure from the things I used to enjoy.

\section{Guilty Feelings}

0 I don't feel particularly guilty.

1 I feel guilty over many things I have done or should have done.

2 I feel quite guilty most of the time.

3 I feel guilty all of the time.

\section{Subtotal Page 1}
6. Punishment Feelings
0 I don't feel I am being punished.
1 I feel I may be punished.
2 I expect to be punished.
3 I feel I am being punished.

\section{Self-Dislike}

0 I feel the same about myself as ever.

1 I have lost confidence in myself.

2 I am disappointed in myself.

3 I dislike myself.

\section{Self-Criticalness}

0 I don't criticize myself or blame myself more than usual.

1 I am more critical of myself than I used to be.

2 I criticize myself for all of my faults.

3 I blame myself for everything bad that happens.

\section{Suicidal Thoughts or Wishes}

0 I don't have any thoughts of killing myself.

1 I have thoughts of killing myself, but I would not carry them out

2 I would like to kill myself.

3 I would kill myself if I had the chance.

\section{Crying}

0 I don't cry anymore than I used to.

1 I cry more than I used to.

2 I cry over every little thing.

3 I feel like crying, but I can't. 


\section{Agitation}

0 I am no more restless or wound up than usual.

1 I feel more restless or wound up than usual.

2 I am so restless or agitated that it's hard to stay still.

3 I am so restless or agitated that I have to keep moving or doing something.

\section{Loss of Interest}

0 I have not lost interest in other people or activities.

$1 \mathrm{I}$ am less interested in other people or things than before.

2 I have lost most of my interest in other people or things.

3 It's hard to get interested in anything.

\section{Indecisiveness}

0 I make decisions about as well as before.

1 I find it more difficult to make decisions than usual.

2 I have much greater difficulty in making decisions than I used to.

3 I have trouble making any decisions.

\section{Worthlessness}

0 I do not feel I am worthless.

1 I don't consider myself as worthwhile and useful as I used to.

2 I feel more worthless as compared to other people.

3 I feel utterly worthless.

\section{Loss of Energy}

0 I have as much energy as ever.

1 I have less energy than I used to have.

2 I don't have enough energy to do very much.

3 I don't have enough energy to do anything.

\section{Changes in Sleeping Pattern}

0 I have not experienced any change in my sleeping pattern.

1a I sleep somewhat more than usual.

$1 b$ I sleep somewhat less than usual.

2 a I sleep a lot more than usual.

$2 \mathrm{~b}$ I sleep a lot less than usual.
17. Irritability

0 I am no more irritable than usual.

1 I am more irritable than usual.

2 I am much more irritable than usual.

3 I am irritable all the time.

\section{Changes in appetite}

0 I have not experienced any change in my appetite.

1a My appetite is somewhat less than usual.

1b My appetite is somewhat greater than usual.

2a My appetite is much less than before.

$2 b$ My appetite is much greater than usual.

3a I have no appetite at all.

$3 b$ I crave food all the time.

\section{Concentration Difficulty}

0 I can concentrate as well as ever.

1 I can't concentrate as well as usual.

2 It's hard to keep my mind on anything for ery long.

3 I find I can't concentrate on anything.

\section{Tiredness or Fatigue}

0 I am no more tired or fatigued than usual.

1 I get more tired or fatigued more easily than usual.

2 I am too tired or fatigued to do a lot of the things I used to do.

3 I am too tired or fatigued to do most of the things I used to do.

\section{Loss of Interest in Sex}

0 I have not noticed any recent change in my interest in sex.

$1 \mathrm{I}$ am less interested in sex than I used to be.

2 I am much less interested in sex now.

3 I have lost interest in sex completely.

3a I sleep most of the day.

3b I wake up 1-2 hours early and I can't get back to sleep.

Subtotal Page 2

Total Score 


\section{Appendix C}

The Self-Efficacy Questionnaire (SEQ-12)

Instructions: The following are some situations in which certain people may be tempted to smoke. Please indicate whether you are sure that you could refrain from smoking in each situation.

Circle the appropriate response choice.

\begin{tabular}{|l|c|c|c|c|c|}
\cline { 2 - 5 } \multicolumn{1}{l|}{} & $\begin{array}{c}\text { not sure } \\
\text { at all }\end{array}$ & $\begin{array}{c}\text { not very } \\
\text { sure }\end{array}$ & $\begin{array}{c}\text { more or } \\
\text { less sure }\end{array}$ & $\begin{array}{c}\text { fairly sure } \\
\text { absolutely } \\
\text { sure }\end{array}$ \\
\hline 1. When I feel nervous & 1 & 2 & 3 & 4 & 5 \\
\hline 2. When I feel depressed & 1 & 2 & 3 & 4 & 5 \\
\hline 3. When I am angry & 1 & 2 & 3 & 4 & 5 \\
\hline 4. When I feel very anxious & 1 & 2 & 3 & 4 & 5 \\
\hline $\begin{array}{l}\text { 5. When I want to think about a difficult } \\
\text { problem }\end{array}$ & 1 & 2 & 3 & 4 & 5 \\
\hline 6. When I feel the urge to smoke & 1 & 2 & 3 & 4 & 5 \\
\hline 7. When having a drink with friends & 1 & 2 & 3 & 4 & 5 \\
\hline 8. When celebrating something & 1 & 2 & 3 & 4 & 5 \\
\hline $\begin{array}{l}\text { 9. When drinking beer, wine or other } \\
\text { spirits }\end{array}$ & 1 & 2 & 3 & 4 & 5 \\
\hline 10. When I am with smokers & 1 & 2 & 3 & 4 & 5 \\
\hline 11. After a meal & 1 & 2 & 3 & 4 & 5 \\
\hline 12. When having coffee or tea & 1 & 2 & 3 & 4 & 5 \\
\hline
\end{tabular}




\section{Appendix D}

\section{Smoking Status Questionnaire}

\section{Smoking Status Week 1:}

1. Have you smoked at all since your

$\overline{\text { (TQD date) }}^{\text {to }}$ (wk1 date) ? (3)
A: No not a puff
B: 1-5 cigarettes
C: More than 5 cigarettes

2. Have you smoked any cigarettes in the last 7 days (even a puff)? (2ㅇ)
A: Yes
B: No

3. CO Measurement: ppm

\section{Smoking Status Week 3:}

1. Have you smoked at all since

$\overline{\text { (TQD) }}^{\text {to }} \overline{\text { (wk3 date) }}^{\text {? }}$
A: No not a puff
B: 1-5 cigarettes
C: More than 5 cigarettes
2. Have you smoked at all since

$\overline{\text { (wk1 date) }}_{\text {to }}^{\text {(wk3 date) }}$ ?
A: No not a puff
B: 1-5 cigarettes
C: More than 5 cigarettes

3. Have you smoked any cigarettes in the last 7 days (even a puff)?

A: Yes

B: No

4. CO Measurement: ppm 


\section{Appendix $\mathrm{E}$ \\ Fagerström Test for Nicotine Dependence}

Instructions: Please read each question carefully and answer how it applies to you.

Circle the appropriate response choice.

1. How soon after you wake up do you smoke your first cigarette?
a) Within 5 minutes
b) 6-30 minutes
c) $31-60$ minutes
d) After 60 minutes

2. Do you find it difficult to refrain from smoking in places where it is forbidden (e.g. in church, at the library, in cinema, ect.)?
a) Yes
b) No

3. Which cigarette would you hate most to give up?
a) The first one in the morning
b) All others
(0)

4. How many cigarettes/day do you smoke?
a) 10 or less
b) $11-20$
c) $21-30$
d) 31 or more

5. Do you smoke more frequently during the first hours after waking than during the rest of the day?
a) Yes
b) No

6. Do you smoke if you are so ill that you are in bed most of the day?
a) Yes
b) No
c) 


\section{Appendix $\mathrm{F}$}

Baseline Demographics and Smoking History Questionnaire

\section{Baseline Demographics}

1. Age:

2. Gender: Male $\square$ Female

3. What is your preferred language? $\square$ English $\square$ French $\square$ Other:

4. Marital status:

$\begin{array}{lll}\square \text { Never married } & \square \text { Married } & \square \text { Living Common Law } \\ \square \text { Divorced } & \square \text { Separated } & \square \text { Widowed }\end{array}$

5. How many years of formal schooling have you completed?

\section{$00000000000000000000000+$}

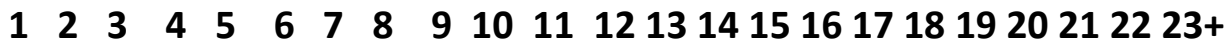

Grade School

High School

College or University

6. What is your employment status?

$\square$ Full-time

$\square$ Homemaker
Part-time

Retired
Unemployed

Disability Leave 
7. What is your gross annual family income?
$\$ 19,999$ or less
$\$ 40,000-\$ 49,999$
$\$ 70,000$ or greater
$\$ 20,000-\$ 29,999$
$\$ 50,000-\$ 59,999$
Prefer not to say
$\$ 30,000-\$ 39,999$
$\$ 60,000-\$ 69,999$

8. What is your ethnic origin or background?
White (Caucasian)
Filipino
West Asian (e.g., Iranian,
Black
Arab Afghan, etc.)
Japanese
South Asian (e.g., East
Latin American

epanese Indian, Pakistani, Sri Lankan, etc.)
Korean
Aboriginal person (e.g., North American Indian,
Chinese Métis, or Inuit Eskimo)

\section{Other:}

\section{Baseline Smoking History}

1. At what age did you smoke your first cigarette? years of age

2. At what age did you begin to smoke cigarettes daily? years of age

3. For about how many years you have smoked every day? (Do not count periods when you did not smoke.) years

4. How many cigarettes do you smoke each day now? cigarettes/day, for years

5. How many people in your household smoke?

6. How many people smoke cigarettes inside your home every day or almost every day? (Include all family members and visitors)

7. For the hours spent inside your home, how many hours per day are you exposed to other people's cigarette smoke? hours/day 
8. How many times have you tried to quit smoking in the past? total quit attempts

9. What is the longest period of time you have quit smoking for? consecutive weeks

10. In the past year,

a. How many times did you stop smoking for at least 24 hours because you were trying to quit?

b. How many of these attempts lasted at least 1 week?

11. Have you ever used any of the following methods to help you stop smoking?

$\begin{array}{lll}\square \text { Acupuncture } & \square \text { Individual } & \square \text { Varenicline (Champix) } \\ \square \text { Cypnosis } & \text { Counselling } & \square \text { Buproprion (Zyban) } \\ \square \text { Laser } & \text { Counselling } & \square \text { Patch } \\ \square \text { Herbal Remedies } & \square \text { Cold turkey } & \square \text { Gum } \\ \square \text { Other } & \square \text { Tapered down } & \square \text { Inhaler } \\ & \end{array}$

